UPADHYAYA, H. D. and R. ORTIZ (2001): Amini core subset for capturing diversity and promoting utilization of chickpea genetic resources in crop improvement. Theor Appl Genet 102: 1292-8.

Vedula, L. S., M. J. Rynkiewicz, H. J. Pyun, R. M. Coates, D. E. Cane and D. W. Christianson (2005):
Molecular recognition of the substrate diphosphate group governs.

Jian, Y., G. Couloures, Z. K. Irena, I. Cutcutache, S. Rozen and T. L. MADDEN (2012): Primer BLAST: A tool to design target specific primers for Polymerase chain reaction. BMC Bioinformatics 13: 134.

\title{
Association mapping for identification of ISSR and AFLP markers linked with resin yield in Himalayan Chir Pine (Pinus roxburghii Sarg.)
}

\author{
By A. RAWAT ${ }^{\left.1,{ }^{*}\right)}$, S. BARTHWAL ${ }^{1)}$, H. S. GinWAL ${ }^{1)}$ and S. B. TRIPATHI ${ }^{2)}$
}

(Received $4^{\text {th }}$ September 2015)

\begin{abstract}
In Pinus roxburghii, marker-trait associations were studied for resin yield using a set of 238 DNA based markers derived from 9 ISSR and 5 AFLP primer pairs. A total of 240 genotypes of $P$. roxburghii from a natural population in Chakrata division (Tiunee range), Uttarakhand (India) were evaluated for resin yield. Based on stable resin production in consecutive years, 53 genotypes that were best representatives of the variation in resin yield ( 0.25 to $8.0 \mathrm{~kg} /$ tree/year) were used for genotyping and association analysis. For carrying out the association studies, two approaches were used. First, using simple linear regression, resin yield was regressed on all 238 available polymorphic markers (148 ISSR markers and 90 AFLP markers) and second, evidence for association was examined applying population structure information using STRUCTURE and STRAT to avoid any spurious associations between a candidate marker and phenotype. In regression analysis, 16 ISSR and 12 AFLP markers showed significant association with resin yield. In the second approach, 18 ISSR and 18 AFLP loci were found

1) Division of Genetics and Tree Propagation, Forest Research Institute, P.O.I.P.E Kaulagarh Road, Dehradun-248195, Uttarakhand, India.

2) Centre for Bioresources and Biotechnology, The Energy and Resources Institute University, New Delhi-21197, India.

*) Author for correspondence: AnITA RAWAT.

Ph: +91-9719408989 Fax: +91-135-2756865

E-Mail: anitasrawat@gmail.com
\end{abstract}

to be associated with resin yield in the absence of population structure out of which 2 ISSR and 3 AFLP loci were common with those associated in regression analysis. After accounting for population structure, 38 ISSR, and 3 AFLP loci revealed association out of which one ISSR and one AFLP locus was found to be common with both simple linear regression and test of association in the absence of population stratification. There was no obvious correlation between population structure and resin yield.

Key words: regression, population structure, structured association test, ISSR, AFLP, Pinus roxburghii.

\section{Introduction}

Pinus roxburghii (Sarg.) commonly called as long leaf pine or Himalayan chir pine is one of the most important conifers found in the lower Himalayan region between latitudes $26^{\circ} \mathrm{N}$ and $36^{\circ} \mathrm{N}$ and longitudes $71^{\circ} \mathrm{E}$ and $93^{\circ} \mathrm{E}$ in subtropical and warm temperate monsoon belts, between 450 to $2300 \mathrm{~m}$ altitudes in Siwaliks and Himalayan main river valleys, from Kashmir to Bhutan (GHILDIYAL et al., 2009). Trees of $P$. roxburghii yield the highest amount of oleoresin in India (COPPEN and HoNE, 1995), which is a commercially important product, having huge export potential. The annual production of resins in India as estimated by the state forest departments was found to be 27,961 tons in 
2009-2010 with an approximate value of 16.306 million USD (FoRESTRY STATISTICS INDIA, 2011). Resin yield is a phenotypic trait and can be scored only in mature trees which are 15-20 years or have attained a diameter greater than 20-25 cm (Coppen and Hone, 1995). Therefore, identification of plus trees for high resin yield through quantitative estimation of the resin yield is highly time consuming. Pines have long gestation periods with vegetative phase extending over hundred years and because of which multiple generations are not readily obtained and traditional approaches of tree improvement involving the identification of mature trees with desirable phenotypes, followed by their incorporation into breeding programs are rather slow processes. However, if it is possible to identify the high resin yielding genotypes at the nursery stage, then plantations can be raised solely for the purpose of resin production. This will reduce the harm to the naturally occurring trees of chir pine in resin tapping as well as the time period and cost required for the quantitative detection.

The identification of trait specific molecular markers has been successfully attempted in many agricultural crops through linkage mapping. Linkage based studies conducted in the past allowed identification of genes/QTLs at distances as large as 10-30 cM from the closest markers, which is hardly suitable either for marker-assisted breeding or for identification/ cloning of functional genes. Furthermore, in linkage based analysis, only few genotypes that are used as parents of mapping populations could be screened for marker-trait associations, placing another limitation. In order to overcome these limitations of linkage based analysis, in the recent past, association studies have been conducted, which not only allow mapping of genes/QTLs with higher level of confidence, but also allow detection of genes/QTLs, which would otherwise escape detection in linkage-based studies (DARVASI et al., 1993; NEALE and SAVOLAINEN, 2004).

In association mapping, unaccounted subdivisions in the sample, referred to as population structure (PRITCHARD et al., 2000a) may result in false positives. The presence of related subgroups in the sample could create covariance among individuals that if not included explicitly in the model; generate biasness in the estimates of allele effects (KENNEDY et al., 1992). Understanding the population structure in an associa- tion panel can effectively avoid spurious associations and improve the accuracy in association mapping (ZHAO et al., 2014). A Bayesian approach for inference of population structure is based on unlinked markers and is implemented in the software STRUCTURE (PRITCHARD et al., 2000a). This program assigns individuals to subpopulations, and that assignment is considered in testing associations of markers with dichotomous traits (PRITCHARD et al., 2000b). Advantages of population basedassociation study over traditional QTL-mapping in bi-parental crosses primarily are due to availability of broader genetic variations with wider background for marker-trait correlations (ABDURAKHMONOV and ABDUKARIMOV, 2008). It results in higher resolution mapping because of the utilization of majority recombination events from a large number of meiosis throughout the germplasm development history. In population based association study, it is possible to exploit historically measured data for any trait(s) and there is no need to develop expensive and tedious bi-parental populations. It makes this approach timesaving and cost-effective (HANSEN et al., 2001; KRAAKMAN et al., 2004; KRAAKMAN et al., 2006).

Work on identification of trait specific molecular markers is essential for future tree improvement programs of Pines. Development of markers for resin production is needed for better utilization and conservation of an important commercial conifer species. In an earlier report, linkage disequilibrium (LD) based association study for resin production was carried out in $P$. roxburghii using microsatellite markers (RAWAT et al., 2014b). Unlike humans and several model systems, such as Mus musculus and Arabidopsis thaliana, in which high-resolution LD maps have been constructed with codominant markers, such as single-nucleotide polymorphisms (SNPs) and microsatellites, many underrepresented species, like forest trees, still heavily rely upon simple and cheap dominant marker techniques. Furthermore, even with codominant, and multiallelic SSR markers, there is a great challenge with assigning correct allelic relationships of multiple band amplicons when diverse, reticulated, and polyploid germplasm resources, lacking historical pedigree information, are genotyped. The dominant markers including Random Amplified Polymorphic DNA (RAPD) (WILliams et al., 1990) and Amplified Fragment Length Polymorphism 
(AFLP) (Vos et al., 1995) can be genotyped arbitrarily from the genome with no need of prior knowledge about the structure and sequence of the genome. There are extensive publications on the use of dominant markers to explore the amount, structure, and distribution of genetic variation in a population (YAN et al., 1999; ZhivotovskY, 1999; Holsinger et al., 2002; MILLER and SCHAAL, 2006) and manage biological resources and diversity in agriculture and forestry (KUANG et al., 1998; SILBIGER et al., 1998; KREMER et al., 2005). Large scale exploitation using old and outdated methods of resin tapping have caused severe damage to the pine trees. The preset study was carried out to find out markers associated with resin production in P. roxburghii so as to facilitate the identification of pine trees with high resin yield at nursery stage and check the damage to naturally occurring pine forests. Some ISSR as well as AFLP markers associated with resin yield were identified. The study also revealed that the variation in resin yield among the genotypes was not attributed to their site of collection or their ancestry highlighting the genetic basis of the trait.

\section{Materials and Methods}

\section{Plant material and field experiment}

P. roxburghii trees were evaluated for resin yield at three sites viz. Chakrata division (Uttarakhand), Nahan division (Himachal Pradesh) and Udhampur division (Jammu and Kashmir) in a study conducted by Forest Research Institute, Dehradun, India (NEGI and MALIK, 2009). The data revealed maximum variation in resin yield in Chakrata division (Uttarakhand). As per the study, correlation of tree diameter, altitude and site quality with resin yield was found to be not significant in Chakrata. Based on these two observations, Chakrata site (Uttarakhand) was selected for carrying out molecular characterization of pine genotypes for the identification of markers associated with resin yield. A total of 240 genotypes of chir pine from Chakrata division (Tiunee range), Uttarakhand were evaluated for resin yield. The experiment was laid in the natural forest of chir pine at an altitude ranging from 1000 to $1500 \mathrm{~m}$ above the mean sea level covering southern aspect (A1) and northern aspect (A2), each with two sites having different site qualities (S1 and S2). For each site quality, three plots ( 0.25 ha each) were selected at random, comprising total area of 0.75 ha. The plots were considered as replications. For each replication, entire area of 0.25 ha was surveyed for the collection of data. Since, the genotypes showing maximum variation in the trait are highly recommended for conducting association studies (ZHAO et al., 2014) so the individuals with similar resin yield were excluded. Fiftythree genotypes that were best representatives of the variation in resin yield were selected for genotyping and association mapping. Geographical details along with the morphological data of the selected trees in terms of diameter, height and annual resin yield is tabulated in Table 1. Young needles or sapwood (in case needles were not available due to extreme height of trees) samples were collected from the site and stored at $-80^{\circ} \mathrm{C}$.

\section{Estimation of resin yield}

Rill method of resin tapping was used keeping the blaze area uniform $(45 \times 20) \mathrm{cm}^{2}$ for all the trees. Month wise resin yield was recorded from the month of June till November and finally the annual resin yield was determined for all the trees (Table 1). The resin yield ranged between 0.25 and $8.0 \mathrm{~kg} /$ tree/year with an average yield of $3 \mathrm{~kg} /$ tree/year. The individuals with resin yield less than $3 \mathrm{~kg} /$ year were grouped as low resin yielders while those with resin yield more than $3 \mathrm{~kg} /$ year were grouped as high resin yielders.

\section{DNA extraction and quantification}

DNA was extracted from young needles using a combination of the methods described by Stange et al. (1998) and Doyle and Doyle (1990) and from the sapwood following a combination of the protocols given by ASIF and CANNON (2005) and Doyle and Doyle (1990). The quality of DNA was tested on $0.8 \%$ agarose gel and the DNA concentration was quantified using BioPhotometer (Eppendorf 6131, Germany). DNA samples were diluted to the required concentration for polymerase chain reaction (PCR) amplification.

\section{ISSR analysis}

Twenty five ISSR primers (University of British Columbia, Biotechnology laboratory, 
Table 1. - Resin yield data of P. roxburghii samples collected from different sites.

\begin{tabular}{|c|c|c|c|c|c|}
\hline S. No. & Tree No. & Location & Diameter $(m)$ & Height (m) & Resin Yield (kg/year) \\
\hline 1 & $\mathrm{~A}-01$ & Southern Aspect, Site Quality 1 & 1.3 & 36.0 & 2.20 \\
\hline 2 & $\mathrm{~A}-02$ & Southern Aspect, Site Quality 1 & 2.3 & 37.0 & 6.50 \\
\hline 3 & A-03 & Southern Aspect, Site Quality 1 & 1.7 & 36.8 & 0.90 \\
\hline 4 & A-06 & Southern Aspect, Site Quality 1 & 1.4 & 34.0 & 1.40 \\
\hline 5 & $\mathrm{~A}-07$ & Southern Aspect, Site Quality 1 & 2.1 & 28.9 & 4.10 \\
\hline 6 & A-09 & Southern Aspect, Site Quality 1 & 2.8 & 33.4 & 5.80 \\
\hline 7 & A-10 & Southern Aspect, Site Quality 1 & 1.6 & 32.0 & 3.30 \\
\hline 8 & $A-12$ & Southern Aspect, Site Quality 1 & 2.5 & 37.0 & 8.00 \\
\hline 9 & A-13 & Southern Aspect, Site Quality 1 & 1.8 & 24.8 & 3.35 \\
\hline 10 & A-19 & Southern Aspect, Site Quality 1 & 1.5 & 35.0 & 5.20 \\
\hline 11 & $A-24$ & Southern Aspect, Site Quality 1 & 1.1 & 23.0 & 2.80 \\
\hline 12 & A-25 & Southern Aspect, Site Quality 1 & 1.5 & 24.5 & 2.90 \\
\hline 13 & A-28 & Southern Aspect, Site Quality 1 & 1.1 & 29.0 & 6.20 \\
\hline 14 & B-02 & Southern Aspect, Site Quality 2 & 2.5 & 29.2 & 2.50 \\
\hline 15 & B-03 & Southern Aspect, Site Quality 2 & 2.6 & 29.0 & 4.90 \\
\hline 16 & B-04 & Southern Aspect, Site Quality 2 & 2.3 & 30.0 & 0.80 \\
\hline 17 & B-06 & Southern Aspect, Site Quality 2 & 1.4 & 31.0 & 4.50 \\
\hline 18 & B-07 & Southern Aspect, Site Quality 2 & 2.1 & 30.0 & 4.30 \\
\hline 19 & B-08 & Southern Aspect, Site Quality 2 & 1.5 & 27.0 & 2.25 \\
\hline 20 & B-09 & Southern Aspect, Site Quality 2 & 2.2 & 27.0 & 4.70 \\
\hline 21 & B-10 & Southern Aspect, Site Quality 2 & 2.6 & 27.0 & 2.00 \\
\hline 22 & B-12 & Southern Aspect, Site Quality 2 & 1.1 & 28.4 & 4.60 \\
\hline 23 & B-13 & Southern Aspect, Site Quality 2 & 1.8 & 28.0 & 3.60 \\
\hline 24 & B-14 & Southern Aspect, Site Quality 2 & 2.5 & 28.0 & 0.25 \\
\hline 25 & B-18 & Southern Aspect, Site Quality 2 & 2.1 & 45.0 & 3.35 \\
\hline 26 & B-19 & Southern Aspect, Site Quality 2 & 1.4 & 37.0 & 2.70 \\
\hline 27 & B-24 & Southern Aspect, Site Quality 2 & 2.5 & 28.0 & 5.70 \\
\hline 28 & B-25 & Southern Aspect, Site Quality 2 & 1.4 & 34.0 & 6.40 \\
\hline 29 & B-26 & Southern Aspect, Site Quality 2 & 1.3 & 28.0 & 2.80 \\
\hline 30 & C-01 & Northern Aspect, Site Quality 1 & 1.5 & 35.0 & 4.20 \\
\hline 31 & C-03 & Northern Aspect, Site Quality 1 & 2.5 & 40.0 & 5.00 \\
\hline 32 & C-04 & Northern Aspect, Site Quality 1 & 1.9 & 42.8 & 2.70 \\
\hline 33 & C-07 & Northern Aspect, Site Quality 1 & 2.5 & 38.0 & 4.50 \\
\hline 34 & C-08 & Northern Aspect, Site Quality 1 & 1.2 & 36.0 & 4.00 \\
\hline 35 & C-09 & Northern Aspect, Site Quality 1 & 2.0 & 39.0 & 5.60 \\
\hline 36 & C-10 & Northern Aspect, Site Quality 1 & 1.5 & 34.0 & 2.25 \\
\hline 37 & C-12 & Northern Aspect, Site Quality 1 & 2.9 & 36.0 & 2.25 \\
\hline 38 & C-15 & Northern Aspect, Site Quality 1 & 1.8 & 35.0 & 2.90 \\
\hline 39 & C-20 & Northern Aspect, Site Quality 1 & 1.5 & 32.0 & 2.90 \\
\hline 40 & D-07 & Northern Aspect, Site Quality 2 & 1.6 & 28.3 & 1.30 \\
\hline 41 & D-08 & Northern Aspect, Site Quality 2 & 1.8 & 29.2 & 1.10 \\
\hline 42 & D-11 & Northern Aspect, Site Quality 2 & 1.6 & 29.5 & 2.60 \\
\hline 43 & D-14 & Northern Aspect, Site Quality 2 & 2.5 & 36.6 & 2.30 \\
\hline 44 & D-24 & Northern Aspect, Site Quality 2 & 1.4 & 29.2 & 1.75 \\
\hline 45 & D-26 & Northern Aspect, Site Quality 2 & 2.2 & 34.2 & 1.80 \\
\hline 46 & D-27 & Northern Aspect, Site Quality 2 & 1.3 & 36.0 & 0.90 \\
\hline 47 & $D-29$ & Northern Aspect, Site Quality 2 & 1.3 & 27.9 & 2.10 \\
\hline 48 & D-30 & Northern Aspect, Site Quality 2 & 2.2 & 40.2 & 1.60 \\
\hline 49 & D-31 & Northern Aspect, Site Quality 2 & 1.5 & 35.0 & 4.20 \\
\hline 50 & D-33 & Northern Aspect, Site Quality 2 & 2.5 & 40.0 & 5.00 \\
\hline 51 & D-37 & Northern Aspect, Site Quality 2 & 2.5 & 38.0 & 4.50 \\
\hline 52 & D-38 & Northern Aspect, Site Quality 2 & 1.2 & 36.0 & 4.00 \\
\hline 53 & D-39 & Northern Aspect, Site Quality 2 & 2.0 & 39.0 & 5.60 \\
\hline
\end{tabular}

Blaze area: $45 \times 20 \mathrm{~cm}^{2}$.

Vancouver, BC, Canada) were initially screened for amplification (Table 2). Based on reproducibility and polymorphism, 9 ISSR markers were used to conduct the present study. PCR was performed in a $20 \mu \mathrm{l}$ reaction volume (HoNG et al., 2007) containing $15 \mathrm{ng}$ of template DNA, 1X Taq buffer, $1.75 \mathrm{mM} \mathrm{MgCl}_{2}, 0.2 \mathrm{mM}$
dNTPs, $0.4 \mu \mathrm{M}$ primer and $0.6 \mathrm{U}$ of Taq DNA polymerase (Bangalore Genei Pvt. Ltd., Bangalore, India). All PCR reactions were performed in a thermal cycler (BIO-RAD, My Cycler) as follows: 5 min. at $94^{\circ} \mathrm{C}$ followed by 40 cycles of 30 sec. at $94^{\circ} \mathrm{C}, 30$ sec. at annealing temperature (primer specific) and $1 \mathrm{~min}$. at $72^{\circ} \mathrm{C}$ and a 
Table 2. - Details of ISSR primers used in the study.

\begin{tabular}{|cllcl|}
\hline S.No. & Primer & Base Sequence $\left(\mathbf{5}^{\prime}-\mathbf{3}^{\prime}\right)$ & $\mathrm{T}_{a}{ }^{*}\left({ }^{\circ} \mathrm{C}\right)$ & \multicolumn{1}{c|}{ Response } \\
\hline $\mathbf{1}$ & UBC2 & ATATATATATATATATG & - & No amplification \\
\hline $\mathbf{2}$ & UBC803 & ATATATATATATATATC & - & No amplification \\
\hline $\mathbf{3}$ & UBC809 & GAGGAGAGAGAGAGAGG & 57.7 & polymorphic \\
\hline $\mathbf{4}$ & UBC820 & GTGTGTGTGTGTGTGTC & 56.8 & polymorphic \\
\hline $\mathbf{5}$ & UBC825 & ACACACACACACACACT & 52.6 & polymorphic \\
\hline $\mathbf{6}$ & UBC843 & CTCTCTCTCTCTCTCTRA & - & No amplification \\
\hline $\mathbf{7}$ & UBC880 & GGAGAGGAGAGGAGA & 48.4 & polymorphic \\
\hline $\mathbf{8}$ & UBC891 & ACTACGACTGTGTGTGTGTGG & - & No amplification \\
\hline $\mathbf{9}$ & UBC809' & AGAGAGAGAGAGAGAGG & 56.8 & polymorphic \\
\hline $\mathbf{1 0}$ & UBC811 & GAGAGAGAGAGAGAGAC & 50 & polymorphic \\
\hline $\mathbf{1 1}$ & UBC812 & GAGAGAGAGAGAGAGAA & - & No amplification \\
\hline $\mathbf{1 2}$ & UBC818 & CACACACACACACACAG & 50 & polymorphic \\
\hline $\mathbf{1 3}$ & UBC846 & CACACACACACACACA(AG)T & 57.7 & polymorphic \\
\hline $\mathbf{1 4}$ & UBC851 & GTGTGTGTGTGTGTGTYG & 56.0 & monomorphic \\
\hline $\mathbf{1 5}$ & UBC852 & TCTCTCTCTCTCTCTCRA & - & No amplification \\
\hline $\mathbf{1 6}$ & UBC854 & TCTCTCTCTCTCTCTCRG & - & No amplification \\
\hline $\mathbf{1 7}$ & UBC855 & ACACACACACACACACYT & - & No amplification \\
\hline $\mathbf{1 8}$ & UBC856 & ACACACACACACACACYA & - & No amplification \\
\hline $\mathbf{1 9}$ & UBC857 & ACACACACACACACACYG & - & No amplification \\
\hline $\mathbf{2 0}$ & UBC858 & TGTGTGTGTGTGTGTGRT & - & No amplification \\
\hline $\mathbf{2 1}$ & UBC859 & TGTGTGTGTGTGTGTGC & - & No amplification \\
\hline $\mathbf{2 2}$ & UBC860 & TGTGTGTGTGTGTGGRA & - & No amplification \\
\hline $\mathbf{2 3}$ & UBC861 & ACCACCACACCACCACC & - & No amplification \\
\hline $\mathbf{2 4}$ & UBC865 & CCGCCGCCGCCGCCGCCG & - & No amplification \\
\hline $\mathbf{2 5}$ & UBC873 & GACAGACAGACAGACA & 51.6 & polymorphic \\
\hline
\end{tabular}

* Ta-annealing temperature at which amplification was recorded.

final extension of $10 \mathrm{~min}$. at $72^{\circ} \mathrm{C}$. Amplified products were electrophoresed on $2 \%(\mathrm{w} / \mathrm{v})$ agarose gel with $1 \mathrm{X}$ TBE buffer. DNA fragments were visualized under UV light and documented with the gel documentation imaging system (GelDoc-It System, UVP Ltd.).

\section{AFLP analysis}

A total of 12 primer combinations were screened for amplification, out of which 5 primer combinations were found to be polymorphic (Table 3). AFLP was carried out using the standard protocol described by Vos et al. (1995) using a commercial kit (Invitrogen) using 250 ng DNA of each accession. All PCR reactions were performed in a Gene Amp PCR 9700 Thermal Cycler. The samples were size-fractionated on $6 \%$ polyacrylamide gels using Sequigen GT (Bio-Rad, Hercules, USA) under denaturing conditions. The fragments were detected by autoradiography.

Table 3. - List of AFLP primer combinations used in the study.

\begin{tabular}{|llll|}
\hline S. No. & Primer combination & & \multicolumn{1}{c|}{ Response } \\
\hline $\mathbf{1}$ & E-AAG X M-CAC & EcoRI-Msel $(+3,+3)$ & poor resolution \\
\hline $\mathbf{2}$ & E-ACC X M-CAA & EcoRI-Msel $(+3,+3)$ & poor resolution \\
\hline $\mathbf{3}$ & E-AGG X M-CAG & EcoRI-Msel $(+3,+3)$ & poor resolution \\
\hline $\mathbf{4}$ & E-AAC X M-CAC & EcoRI-Msel $(+3,+3)$ & no amplification \\
\hline $\mathbf{5}$ & E-AAG X M-CAA & EcoRI-Msel $(+3,+3)$ & no amplification \\
\hline $\mathbf{6}$ & E-ACA X M-CTA & EcoRI-Msel $(+3,+3)$ & polymorphic \\
\hline $\mathbf{7}$ & E-ACA X M-CAGT & EcoRI-Msel $(+3,+4)$ & polymorphic \\
\hline $\mathbf{8}$ & E-ACA X M-CTAC & EcoRI-Msel $(+3,+4)$ & monomorphic \\
\hline $\mathbf{9}$ & E-ACA X M-CTGC & EcoRI-Msel $(+3,+4)$ & polymorphic \\
\hline $\mathbf{1 0}$ & E-AAG X M-CAGT & EcoRI-Msel $(+3,+4)$ & monomorphic \\
\hline $\mathbf{1 1}$ & E-AAG X M-CTAC & EcoRI-Msel $(+3,+4)$ & polymorphic \\
\hline $\mathbf{1 2}$ & E-AAG X M-CTGC & EcoRI-Msel $(+3,+4)$ & polymorphic \\
\hline
\end{tabular}




\section{Gel scoring and data analysis}

Scoring of data

The profiles produced by ISSR and AFLP markers were scored manually. Each allele was scored as present (1) or absent (0) for each of the ISSR and AFLP loci.

\section{Statistical analysis}

Genotypic data obtained for different markers have been used for assessing the discriminatory power of primers and determining the utility of ISSR and AFLP marker systems by evaluating various marker attributes such as percent polymorphism, polymorphism information content (PIC), effective multiplex ratio (EMR), marker index (MI) and resolving power (RP) (RAWAT et $a l ., 2014 a)$.

\section{Cluster analysis}

Genetic dissimilarity was calculated based on Jaccard's dissimilarity index using the software DARwin ver 5.0.158 (PERRIER and JACQUEMOUDCOLLET, 2006), where " 0 " and " 1 " were standardized as the least and maximum dissimilarity respectively. The dissimilarity matrix was used for tree construction following hierarchical clustering method using UPGMA algorithm implemented in DARwin. Confidence limits of different clades were tested by bootstrapping 1000 times to assess the repetitiveness of genotype clustering (FELSENSTEIN, 1985).

\section{Genetic structure analysis}

For the analysis of population structure, a model-based (Bayesian) cluster analysis was performed based on ISSR and AFLP markers. This analysis was implemented in the software STRUCTURE ver 2.2 (PRITCHARD et al., 2000a and 2000b) which identify subgroups of accessions with distinct allele frequencies within the germplasm. STRUCTURE computes a $Q$ matrix defined as an $n \times p$ population structure incidence matrix where $\mathrm{n}$ is the number of individuals assayed and $p$ is the number of sub-populations assumed; $Q$ is inferred from Pritchard's STRUCTURE estimates with $p$ (Pritchard's K) sub-populations. The model based cluster analysis was used to test the hypothesis of one to ten sub-populations $(K=1$ to $\mathrm{K}=10$ ) assuming admixture and correlated allele frequencies in different subpopulations. 100,000 iterations and a burn-in period of
100,000 were carried out for each run. Ten independent STRUCTURE runs were performed separately for each $K$. The value of $K$ was detected by an ad hoc quantity based on the second order rate of change of the likelihood function with respect to $K(\Delta \mathrm{K})$ (EvANNO et al., 2005)

$$
\Delta \mathrm{K}=\mathrm{m}(|\mathrm{L}(\mathrm{K}+1)-2 \mathrm{~L}(\mathrm{~K})+\mathrm{L}(\mathrm{K}-1)|) / \mathrm{s}[\mathrm{L}(\mathrm{K})]
$$

Where, $\mathrm{L}(\mathrm{K})$ is $\mathrm{Ln} \mathrm{P}(\mathrm{D})$, the posterior probability of the data for a given $\mathrm{K}, \operatorname{Pr}(\mathrm{X} \mid \mathrm{K})$ in STRUCTURE output, $\mathrm{s}[\mathrm{L}(\mathrm{K})]$ is the standard deviation of $\mathrm{L}(\mathrm{K})$, and $\mathrm{m}$ is mean in the parenthesis. $\Delta \mathrm{K}$ shows a clear peak at the true value of $\mathrm{K}$.

\section{Analysis of molecular variance (AMOVA)}

The genetic differentiation was inferred by AMOVA according to ExCOFFIER et al. (1992) using the software Arlequin version 3.11 (EXCOFFIER et al., 2005). The type of hierarchial AMOVA implemented here was with genotypic data, one group of populations and number within individual level. AMOVA was carried out in two ways: i) AMOVA by collection site wherein the 53 selected genotypes of $P$. roxburghii were divided into four groups based on their site of collection and ii) AMOVA by resin yield where the genotypes were divided into three groups viz. high resin yielding $(>3 \mathrm{~kg}$ year $\left.{ }^{-1}\right)$; medium resin yielding $\left(2.5-3 \mathrm{~kg}^{-}\right.$year $\left.^{-1}\right)$ and low resin yielding $\left(<2.5 \mathrm{~kg}\right.$ year $\left.^{-1}\right)$. This technique treats genetic distances as deviations from a group mean position, and uses squared deviations as variances. The total sum of squares of genetic distances can then be partitioned into components that represent the within population and among population mean squares.

\section{Marker trait association analysis}

Two different approaches were followed for detecting the marker-trait associations: stepwise backward regression analysis using the software SPSS ver. 16 (Statistical Package for Social Sciences) and structured population association test using the software STRAT ver 1.1 with and without accounting for population structure.

\section{Stepwise linear regression analysis}

Stepwise backward regression was carried out to find out the markers showing significant 
association with resin yield. For simple linear regression, resin yield data was regressed on whole 1-0 binary marker data for each individual marker using the software SPSS ver. 16 (Roy et al., 2006). The total number of polymorphic bands ' $\mathrm{T}$ ' for ISSR and AFLP markers showing significant association and the percentage of variation ' $R^{2}$ ' in resin yield explained by each marker was calculated.

\section{Structured Association Test (STRAT)}

STRAT without accounting for population structure

The program STRAT (PRITCHARD et al., 2000) was used to perform tests of association in structured populations. It was assumed that there is a sample of unrelated case (low resin) and control (high resin) individuals from one or more subpopulations, possibly with some level of admixture. The software STRAT ver 1.1 was run without accounting for the ancestral relationship among the genotypes. The markers showing association with the trait at 5\%,1\% and $0.1 \%$ level of probability were accepted as significant.

\section{STRAT after accounting for population structure}

The software STRAT ver 1.1 was used to test for association at each locus, conditional on the ancestry of the individuals in the sample (as estimated by the software STRUCTURE). The markers showing association with the trait at 5, 1 and 0.1 per cent level of probability were accepted as significant. Finally, the markers which consistently showed associations in both the runs (with and without population structure) were considered to be associated with the trait under investigation.

\section{Results}

\section{Cluster analysis using ISSR markers}

The hierarchial clustering using UPGMA algorithm implemented in the software DARwin did not reveal any distinct major clusters. However, four small clusters could be identified in which the grouping was according to the resin yield of genotypes (Fig. 1). Cluster-I grouped six genotypes together (B-6, B-7, C-7, A-13, A-10 and A-7) with a bootstrap value of
78. All of these genotypes had high resin yield (above $3 \mathrm{~kg}$ year ${ }^{-1}$ ). Cluster-II with a bootstrap value of 95 grouped five genotypes together (pooled DNA of low resin yielders, B-26, B-2, B-19 and C-10) all of which had low resin yield (below $3 \mathrm{~kg}$ year ${ }^{-1}$ ). Cluster-III grouped four high resin yielders together (B-3, D-37, A-2 and A-9) with a bootstrap value of 94 . Cluster-IV grouped eight low resin yielders together (B-10, D-30, D-8, A-6, C-12, D-7, D-29 and B-8) with a bootstrap value of 99 .

The genetic dissimilarity index calculated between samples ranged from 0.21 to 0.73 suggesting a high genetic diversity among the genotypes of $P$. roxburghii used in the study. The genotypes B-4 (0.8 kg year $\left.{ }^{-1}\right)$ and B-14 $\left(0.25 \mathrm{~kg}\right.$ year $\left.^{-1}\right)$ both having low resin yield were found to be most similar. On the other hand, the genotypes B-3 (4.9 kg year $\left.{ }^{-1}\right)$ and $\mathrm{D}-14\left(2.3 \mathrm{~kg}\right.$ year $\left.^{-1}\right)$ were found to be the most dissimilar from each other.

\section{Cluster analysis using AFLP markers}

The UPGMA based dendrogram revealed three broad clusters where the genotypes clustered together on the basis of resin yield (Fig. 2). Cluster-I with a bootstrap value of 89 grouped twenty-four genotypes together out of which nineteen were high resin yielders $(>3 \mathrm{~kg}$ year ${ }^{-1}$ ) and only five genotypes had low resin yield $\left(<3 \mathrm{~kg}\right.$ year $\left.^{-1}\right)$. Cluster-II with a bootstrap value of 88 grouped eleven genotypes all of which had low resin yield except B-18. ClusterIII with a bootstrap value of 92 grouped seven genotypes together all of which were low resin yielders except B-13.

The genetic dissimilarity index was generated for $P$. roxburghii genotypes. The dissimilarity coefficient ranged from 0.01 to 0.22 suggesting a low genetic diversity among the genotypes of $P$. roxburghii used in the study. The genotypes A-7 (4.1 kg year $\left.{ }^{-1}\right)$ and B-9 (4.7 kg year ${ }^{-1}$ ) both of which had high resin yield were found to be most similar, whereas B-8 (2.2 kg year $\left.{ }^{-1}\right)$ and D-24 (1.7 kg year $\left.{ }^{-1}\right)$ were found to be the most dissimilar genotypes.

\section{Genetic structure analysis}

Genetic structure analysis using ISSR markers

According to the STRUCTURE results, the log likelihood steadily improved until $\mathrm{K}=5$, and then continued to increase slightly until $K=9$ 


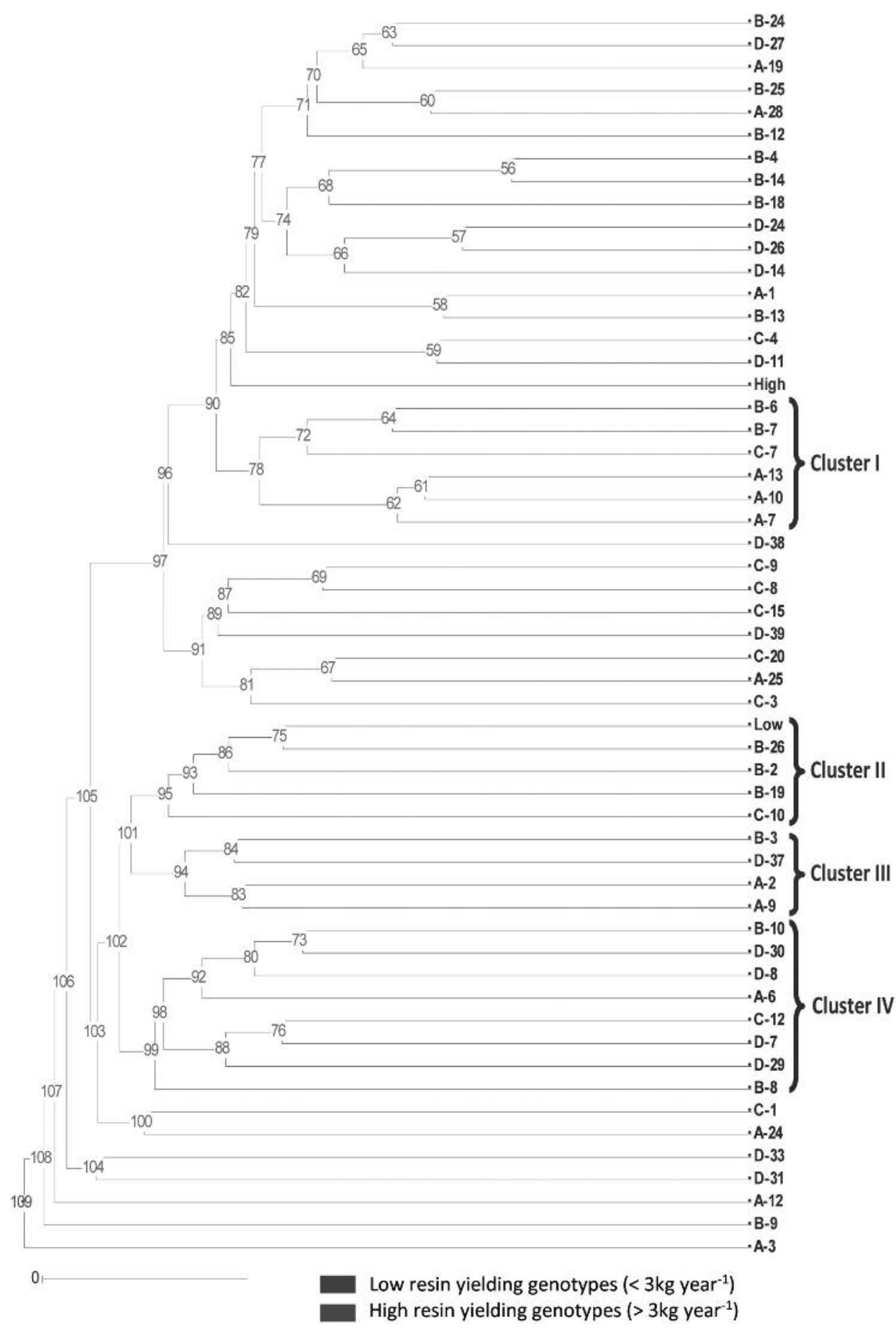

Figure 1. - Dendrogram showing genetic relationship among $P$. roxburghii genotypes varying in resin yield using ISSR markers.

and then leveled off (Fig. 3a). The results showed that the peak value of Evanno's $\Delta \mathrm{K}$ was at $\mathrm{K}=5$, suggesting five genetic clusters (Fig. $3 b$ ). With five as the optimum population structure, inferred ancestries ( $\mathrm{Q}$ matrix) of individuals were determined. Each individual is represented by a vertical line broken into $\mathrm{K}$ colored segments, with lengths proportional to each of the $\mathrm{K}$ inferred clusters.
Beyond $K=5$, the probability of the data did not peak and hence it was considered that five clusters captured the entire divisions of the sample (Fig. 4a). In total, thirty genotypes (56.60\% out of 53 genotypes) were clearly assigned to each single population, where $80 \%$ of their inferred ancestry was derived from one of the model populations, whereas twenty-three genotypes (43.4\% out of 53 genotypes) in the 


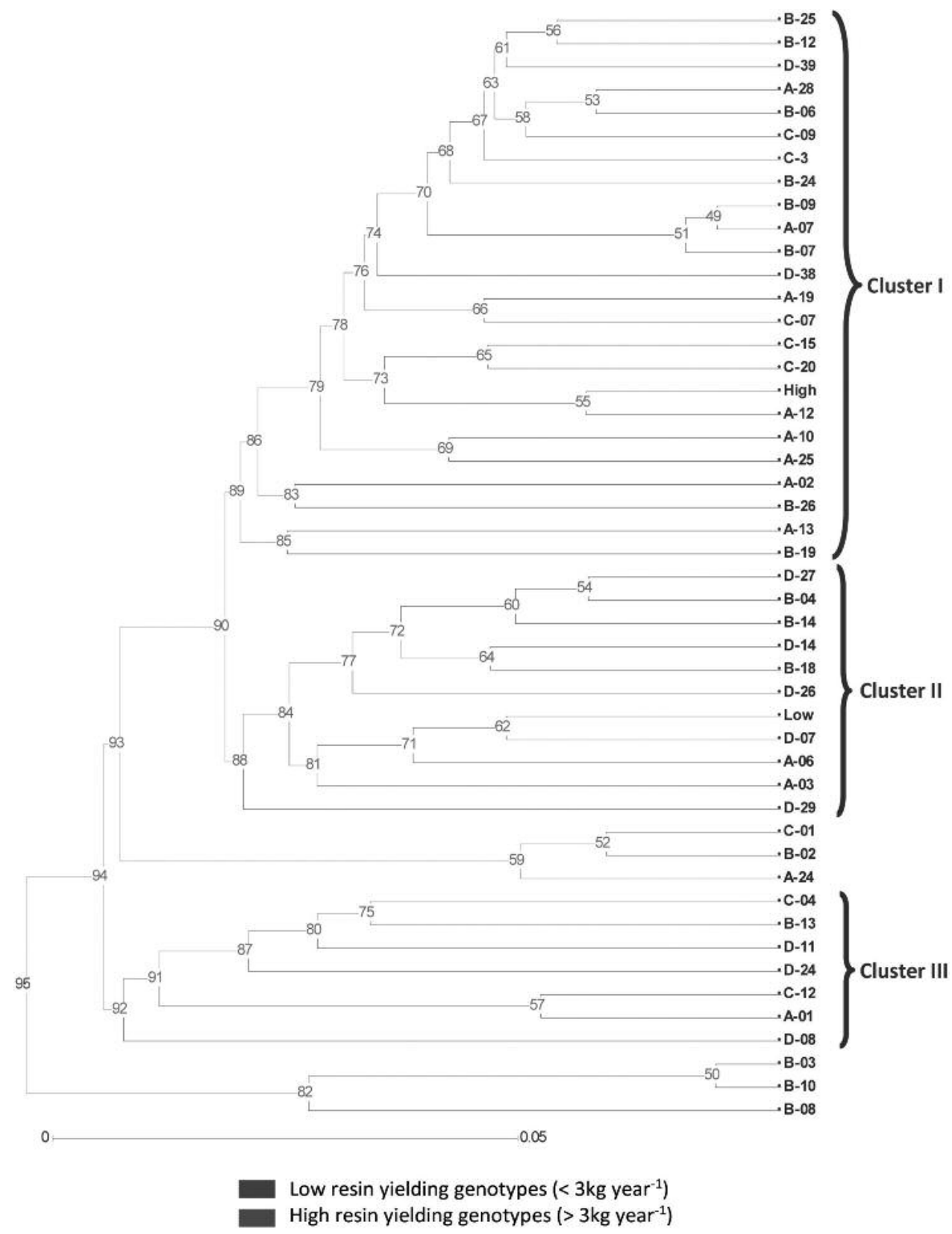

Figure 2. - Dendrogram showing genetic relationship among $P$. roxburghii genotypes varying in resin yield using AFLP markers.

sample were categorized as having admixed ancestry. Each cluster had ten individuals on an average, the highest in cluster 1 and the least in cluster 4 . Clusters 1 to 5 had $F_{\text {ST }}$ values 0.42 , $0.27,0.32,0.48$ and 0.36 respectively. The distribution of $P$. roxburghii genotypes into five sub-populations had no correlation with their resin yield (Fig. $4 b$ ).

Genetic structure analysis using AFLP markers

As per the STRUCTURE results, the log likelihood steadily improved until $\mathrm{K}=5$, and then continued to increase slightly until $K=10$
(Fig. 5a). The results showed that the peak value of Evanno's $\Delta \mathrm{K}$ was at $\mathrm{K}=5$, suggesting five genetic clusters (Fig. 5b). With five as the optimum population structure, inferred ancestries ( $Q$ matrix) of individuals were determined.

Beyond $K=5$, the probability of the data did not peaked and hence it was considered that five clusters captured the entire divisions of the sample (Fig. 6a). In total, twenty-three genotypes (50 per cent out of 46 genotypes) were clearly assigned to each single population, where 80 per cent of their inferred ancestry was 


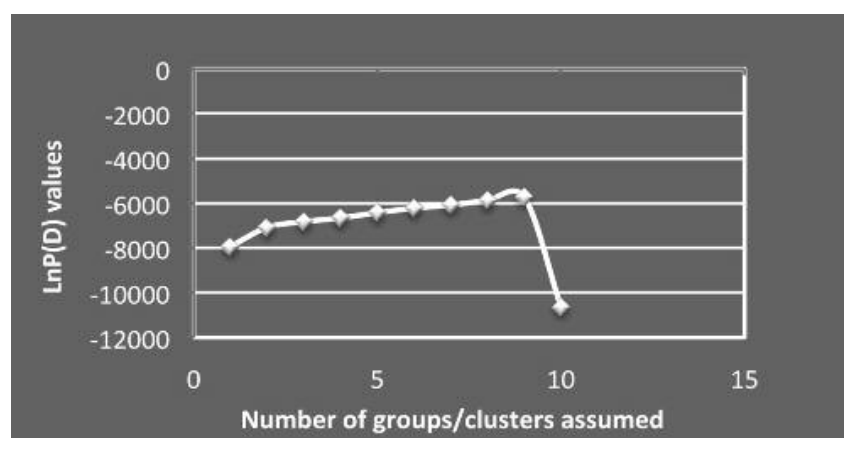

Fig. 3a. - Bayesian posterior probability of data $[\mathrm{LnP}(\mathrm{D})]$ with increasing $\mathrm{K}$ for ISSR markers.

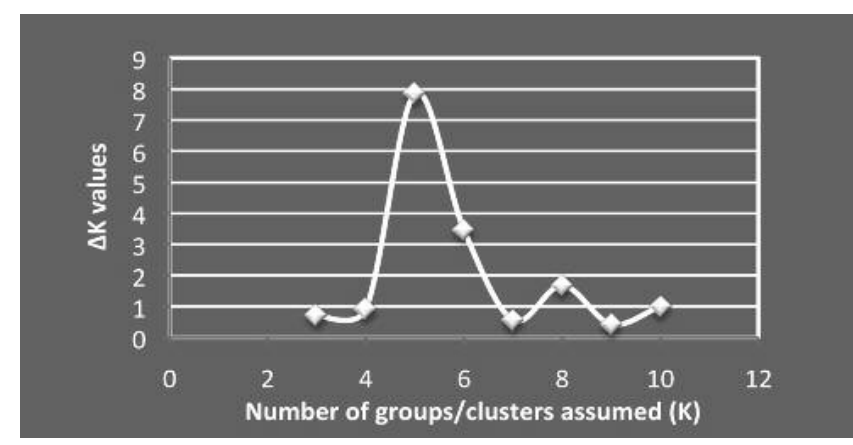

Fig. 3b. - Magnitude of $\Delta \mathrm{K}$ as a function of $\mathrm{K}$ for ISSR markers.

Legend for figures 3a and 3b: As per the results revealed by STRUCTURE, the posterior probability of data, LnP(D), steadily improved until $\mathrm{K}=5$, and then continued to increase slightly until $\mathrm{K}=9$ and then leveled off (Fig. 3a). Based on the four steps for the graphical method allowing detection of the true number of groups $\mathrm{K}$ suggested by EvANNo et al. (2005), true value for $\mathrm{K}$ was detected. The height of modal value of the distribution of $\Delta \mathrm{K}$ (the second order rate of change of the likelihood function with respect to $\mathrm{K}$ ) located at $\mathrm{K}$ indicated the strength of the signal detected by Structure. With respect to $\mathrm{K}$, $(\Delta \mathrm{K})$ showed a clear peak at the true value of $\mathrm{K}$. The real structure showing a clear peak of the genotypes was set at $\mathrm{K}=5$ (Fig. $3 b$ ).

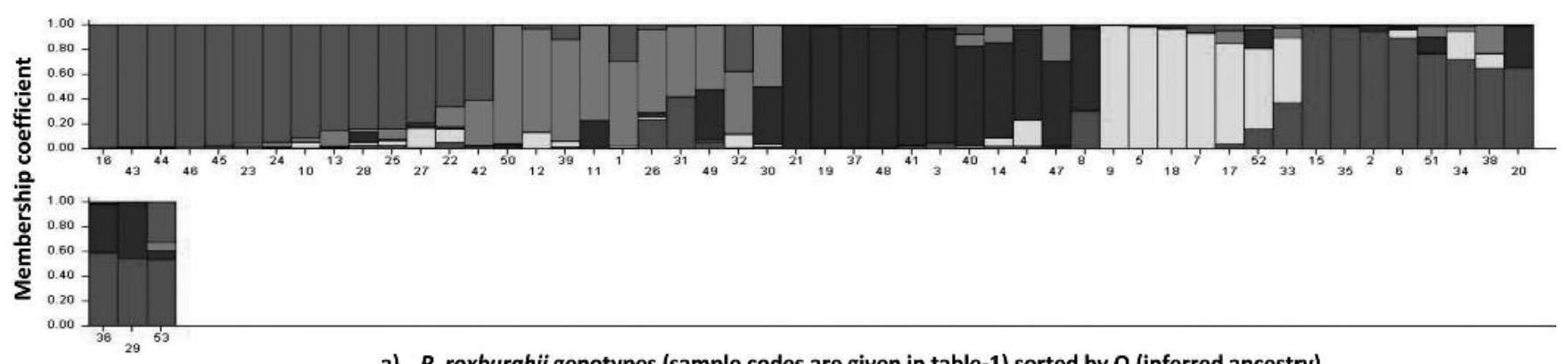

a) P. roxburghii genotypes (sample codes are given in table-1) sorted by $Q$ (inferred ancestry)

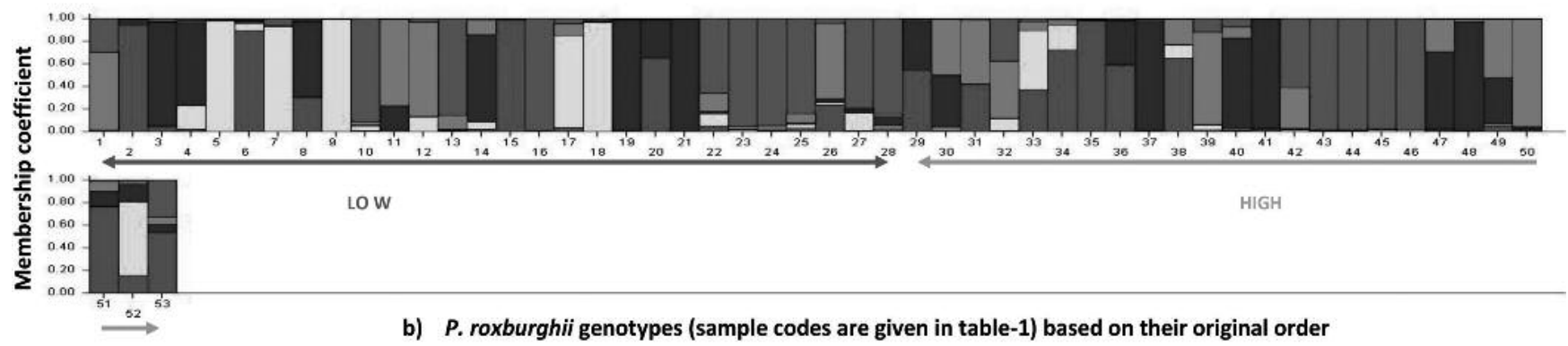

Figure 4. - Estimated genotypic structure plot for all the genotypes using ISSR markers.

The graph is based on Structure run of real set K estimated for ISSR data. Each genotype is represented by a bar, partitioned into different segments corresponding to its membership coefficient in inferred clusters. Each colour represesnts a different cluster, and black segments separate the different genotypes. Left-to-right colour grouping represented in plot is in accordance with the estimated cluster ID.

derived from one of the model populations, whereas twenty-three genotypes (50 per cent out of 46 genotypes) in the sample were categorized as having admixed ancestry. Each cluster had 9 individuals on an average, the highest in cluster 4 and the least in cluster 5 . Clusters 1 to 5 had $F_{\text {ST }}$ values $0.43,0.62,0.53,0.57$ and 0.39 respectively. As in case of ISSR marker system, the distribution of $P$. roxburghii genotypes into the five sub-populations had no correlation with their resin yield (Fig. 6b).

\section{Partitioning of variance using ISSR markers}

AMOVA analysis revealed that 99.4 per cent of the total variation in studied populations of 


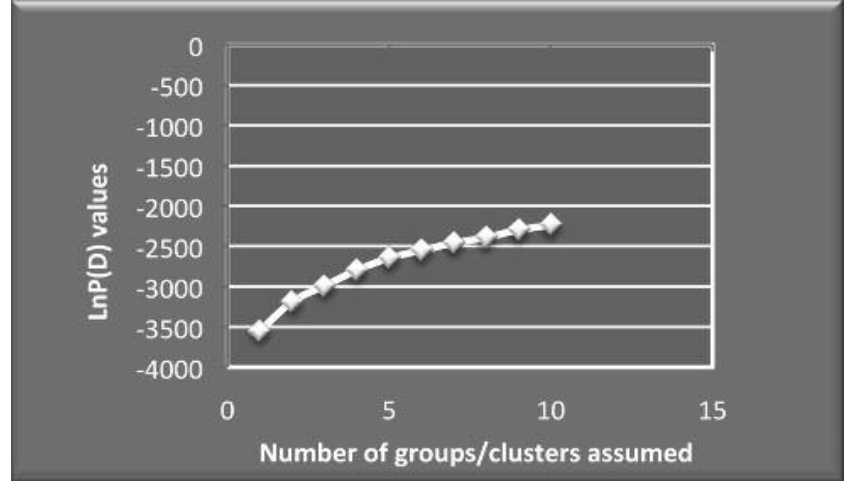

Fig. 5a. - Bayesian posterior probability of data [LnP(D)] with increasing $\mathrm{K}$ for AFLP markers.

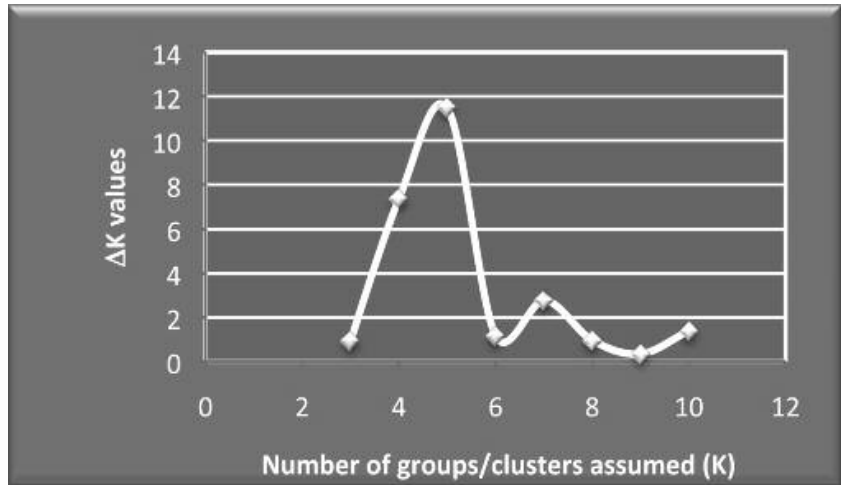

Fig. 5b. - Magnitude of $\Delta \mathrm{K}$ as a function of $\mathrm{K}$ for AFLP markers.

Legend for figures 5a and 5b: As per the results revealed by STRUCTURE, the posterior probability of data, LnP(D), steadily improved until $\mathrm{K}=5$, and then continued to increase slightly until $\mathrm{K}=10$ (Fig. $5 a$ ). Based on the four steps for the graphical method allowing detection of the true number of groups ' $\mathrm{K}$ ' suggested by EvanNo et al. (2005), true value for $\mathrm{K}$ was detected. The height of modal value of the distribution of $\Delta \mathrm{K}$ (the second order rate of change of the likelihood function with respect to $\mathrm{K}$ ) located at $\mathrm{K}$ indicated the strength of the signal detected by STRUCTURE. With respect to $\mathrm{K},(\Delta \mathrm{K})$ showed a clear peak at the true value of $\mathrm{K}$. The real structure showing a clear peak of the genotypes was set at $\mathrm{K}=5$ (Fig. $5 b$ ).

P. roxburghii was structured within populations and only 0.59 per cent was among populations (Table 4). Similarly, it revealed that 95.17 per cent of variation with respect to the resin yield lies within populations and rest 4.83 per cent variation was among populations. There was negligible population genetic differentiation $\left(F_{\mathrm{ST}}=0.005\right)$ between the studied populations for the molecular variation. However the population genetic differentiation was moderate for resin yield $\left(F_{\mathrm{ST}}=0.048\right)$ (Table 4$)$ in $P$. roxburghii.

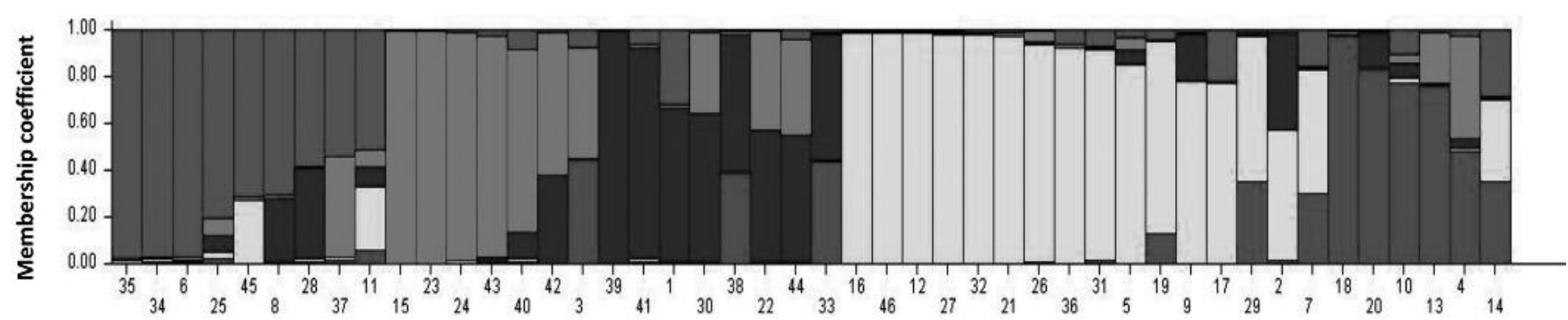

a) P. roxburghii genotypes (sample codes are given in Table-1) sorted by $Q$ (inferred ancestry)

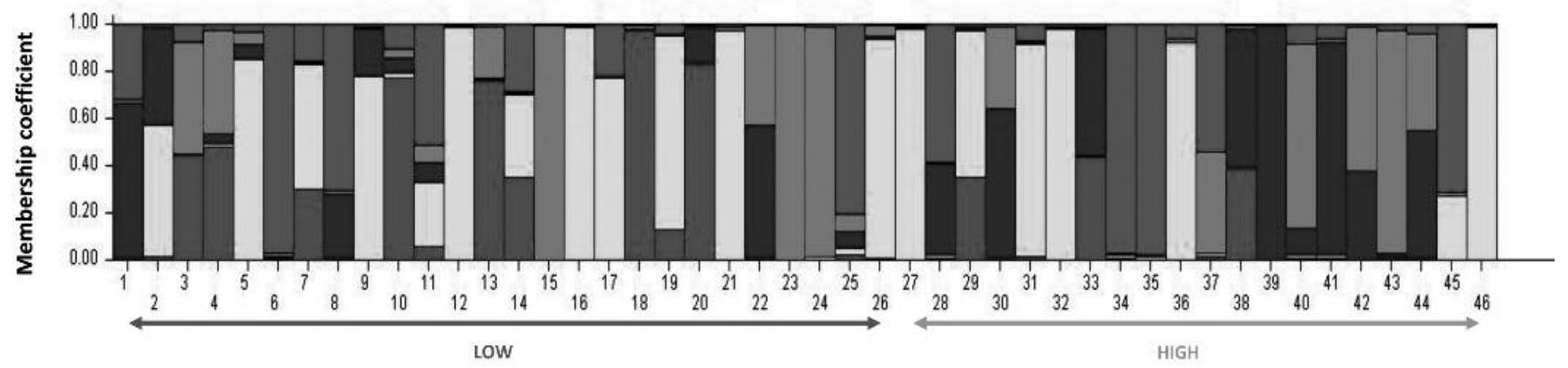

b) P. roxburghii genotypes (sample codes are given in Table-1) based on their original order

Figure 6. - Estimated genotypic structure plot for all the genotypes of P. roxburghii using AFLP markers.

The graph is based on Structure run of real set K estimated for AFLP data. Each genotype is represented by a bar, partitioned into different segments corresponding to its membership coefficient in inferred clusters. Each colour represesnts a different cluster, and black segments separate the different genotypes. Left-to-right colour grouping represented in plot is in accordance with the estimated cluster ID 
Partitioning of variance using AFLP markers

AMOVA analysis revealed that 95.09 per cent of the total variation in studied populations of P. roxburghii was structured within populations and only 4.91 per cent was among populations (Table 4). Similarly, it revealed that 75.77 per cent of variation with respect to the resin yield lies within populations and rest 24.23 per cent variation was among populations. There was negligible population genetic differentiation $\left(F_{\mathrm{ST}}=0.04\right)$ between the studied populations for the molecular variation. However the population genetic differentiation was high for resin yield $\left(F_{\mathrm{ST}}=0.24\right)($ Table 4$)$.

\section{Marker trait association analysis using ISSR markers}

\section{Regression analysis}

Using stepwise backward linear regression, resin yield was regressed on all 148 available polymorphic ISSR loci with a set of fifty-three $P$. roxburghii genotypes. Significant regression $(\mathrm{p}<0.001)$ was observed for a total of sixteen out of 148 polymorphic ISSR loci. The details of ISSR loci found to be associated with resin yield is provided in Table 7. Among the associated loci, $50 \%$ (8 out of 16) were derived from ISSR primer UBC873. The associated loci together accounted for 87.53 per cent of the phenotypic variation in resin yield. Table 5 shows the analysis of variance involving simple linear regression of 148 polymorphic ISSR loci on resin yield.

\section{Structured association test (STRAT) using ISSR markers}

STRAT assuming no population structure

Out of 162 DNA fragments derived from nine ISSR primers, 148 polymorphic loci were assessed for genetic association with the trait. Under the assumption of no population structure, a total of thirty-four out of the 148 polymorphic loci were found to show significant association with resin yield. After correction for false discovery rate, 18 loci were found to be significantly associated (Table 7). As revealed by regression analysis, maximum number of loci $(44.44 \%)$ associated with resin yield were those derived from ISSR primer UBC873. Two of the associated loci (UBC873 1319 and UBC873661), both derived from ISSR primer UBC873 were found to be common with those identified by regression analysis showing their strong association with the trait.

\section{STRAT considering population structure}

After accounting for population stratification, some of the associated loci survived controlling

Table 4. - AMOVA by collection sites and resin yield using ISSR and AFLP marker systems.

\begin{tabular}{|llccll|}
$\begin{array}{l}\text { Marker } \\
\text { system }\end{array}$ & \multicolumn{1}{c}{ Categories } & $\begin{array}{c}\text { Variation within } \\
\text { populations }\end{array}$ & $\begin{array}{c}\text { Variation among } \\
\text { populations }\left(F_{\text {ST }}\right)\end{array}$ & $F_{\text {ST }}$ & p-value \\
\hline ISSR & Collection sites $^{\mathrm{a}}$ & 99.41 & 0.59 & 0.0058 & $\mathrm{p}>0.1$ \\
\hline & Resin yield $^{\mathrm{b}}$ & 95.17 & 4.83 & $0.0483^{* * *}$ & $\mathrm{P}<0.001$ \\
\hline AFLP & Collection sites $^{\mathrm{a}}$ & 95.09 & 4.91 & 0.0491 & $\mathrm{p}>0.1$ \\
\hline & Resin yield $^{\mathrm{b}}$ & 75.77 & 24.23 & $0.2422^{* * *}$ & $\mathrm{P}<0.001$ \\
\hline
\end{tabular}

The type of hierarchial AMOVA implemented here was with genotypic data, one group of populations and no. within individual level.

a collection sites: four sites differing in altitude, aspect and site quality.

${ }^{\mathrm{b}}$ resin yield: resin yield was grouped as low $\left(<2.5 \mathrm{~kg} \mathrm{year}^{-1}\right)$, medium $\left(2.5-3.0 \mathrm{~kg} \mathrm{year}^{-1}\right)$ and high (> $\left.3.0 \mathrm{~kg} \mathrm{year}^{-1}\right)$.

Table 5. - Details of analysis of variance involving simple linear regression for resin yield using 148 ISSR and 90 AFLP loci.

\begin{tabular}{|c|c|c|c|c|c|c|}
\hline Marker & Trait & Source of variance & df & Mean square & $F$ & $p$-value \\
\hline \multirow[t]{3}{*}{ ISSR } & Resin yield & Regression & 16 & 8.422 & 15.365 & $<0.001$ \\
\hline & & Residual & 35 & 0.548 & & \\
\hline & & Total & 51 & & & \\
\hline \multirow[t]{3}{*}{ AFLP } & Resin yield & Regression & 20 & 5.469 & 3.202 & 0.006 \\
\hline & & Residual & 20 & 1.708 & & \\
\hline & & Total & & 40 & & \\
\hline
\end{tabular}

df stands for degree of freedom. 
Table 6. - Table-6 Effect of population stratification on strength of association of ISSR and AFLP loci.

\begin{tabular}{|llcc|}
\hline S.No. & Primer & $\begin{array}{c}\text { p-adjusted } \\
\text { (without population structure) }\end{array}$ & $\begin{array}{c}\text { p-adjusted } \\
\text { (with population structure) }\end{array}$ \\
1 & UBC809849 & $0.010^{*}$ & $0.018^{*}$ \\
$\mathbf{3}$ & UBC809758 & $0.000^{* * *}$ & $0.043^{*}$ \\
4 & UBC818428 & $0.000^{* * *}$ & $0.043^{*}$ \\
5 & UBC8731319 & $\mathbf{0 . 0 0 0 * * *}$ & $\mathbf{0 . 0 0 0 ^ { * * * }}$ \\
$\mathbf{6}$ & UBC873534 & $0.024^{*}$ & $0.011^{*}$ \\
\hline
\end{tabular}

* and ${ }^{* * *}$ indicate significant at $5 \%$ and $0.1 \%$ level of probability.

for population stratification whereas others lose their significance. Fifty-one loci showed significant association with resin yield but after FDR correction, thirty nine loci showed significant association. Five loci (UBC809 ${ }_{849}, \mathrm{UBC} 809_{758}$, UBC818 $428, \mathrm{UBC}_{473_{1319} \text { and UBC873 }}$ (334) were common to those identified even in the absence of population structure however with either similar or different (increased or decreased) strength of association. Although, population stratification had no considerable affect on the strength of association of 3 loci (UBC809 ${ }_{758}$, UBC $873_{1319}$ and UBC873 534 ), the strength of association was reduced for $\mathrm{UBC} 18_{428}$ (Table 6 ). The locus UBC $873_{1319}$ associated with resin yield in structured association also showed significant association with the same strength in the absence of population structure by STRAT

Table 7. - List of markers/loci showing association with resin yield.

\begin{tabular}{|c|c|c|c|}
\hline Marker & Statistical method used & Associated marker & Locus/Loci \\
\hline \multirow[t]{5}{*}{ ISSR } & Simple Linear regression & UBC820 & $\mathrm{L}_{432}$ \\
\hline & & UBC811 & $\mathrm{L}_{985}, \mathrm{~L}_{832}, \mathrm{~L}_{592}$ \\
\hline & & UBC818 & $\mathrm{L}_{1273}, \mathrm{~L}_{904}, \mathrm{~L}_{705}$ \\
\hline & & UBC846 & $\mathrm{L}_{680}$ \\
\hline & & UBC873 & $L_{1182}, L_{1319}, L_{1057}, L_{895}, L_{800}, L_{680}, L_{661}, L_{308}$ \\
\hline \multirow[t]{7}{*}{ ISSR } & STRAT without structure & UBC809 & $\mathrm{L}_{849}, \mathrm{~L}_{758}$ \\
\hline & & UBC825 & $\mathrm{L}_{847}, \mathrm{~L}_{474}$ \\
\hline & & UBC809' & L941 \\
\hline & & UBC811 & $\mathrm{L}_{819}, \mathrm{~L}_{419}$ \\
\hline & & UBC818 & L428 \\
\hline & & UBC846 & $\mathrm{L}_{1339,} \mathrm{~L}_{407}$ \\
\hline & & UBC873 & $\mathrm{L}_{1319}, \mathrm{~L}_{801}, \mathrm{~L}_{758}, \mathrm{~L}_{661}, \mathrm{~L}_{534}, \mathrm{~L}_{520}, \mathrm{~L}_{557}, \mathrm{~L}_{457}$ \\
\hline \multirow[t]{8}{*}{ ISSR } & STRAT with structure & UBC809 & $\mathrm{L}_{1008}, \mathrm{~L}_{849}, \mathrm{~L}_{758}, \mathrm{~L}_{680}, \mathrm{~L}_{634}$ \\
\hline & & UBC825 & $\mathbf{L}_{1028}, \mathrm{~L}_{750}, \mathrm{~L}_{618}, \mathrm{~L}_{604}, \mathrm{~L}_{510}$ \\
\hline & & UBC880 & $L_{913}$ \\
\hline & & UBC809' & $\mathrm{L}_{1328,} \mathrm{~L}_{861}$ \\
\hline & & UBC811 & $L_{634}, L_{481}, L_{465}, L_{434}, L_{397}, L_{377}, L_{313}$ \\
\hline & & UBC818 & $L_{1273}, L_{1014}, L_{783}, L_{571}, L_{509}, L_{467}, L_{453}, L_{428}, L_{404}$ \\
\hline & & UBC846 & $L_{997} L_{272}$ \\
\hline & & UBC873 & $\mathbf{L}_{1356,} \mathbf{L}_{1319}{ }^{*}, \mathrm{~L}_{1057}, \mathrm{~L}_{870}, \mathrm{~L}_{800}, \mathrm{~L}_{578}, \mathrm{~L}_{534}, \mathbf{L}_{410}$ \\
\hline \multirow[t]{5}{*}{ AFLP } & Simple Linear regression & $E_{A C A} M_{C T G C}$ & $\mathrm{~L}_{55}, \mathrm{~L}_{326}$ \\
\hline & & $E_{A C A} M_{C T A}$ & $L_{51}, L_{286}, L_{352}$ \\
\hline & & $E_{A A G} M_{C A G T}$ & $\mathrm{~L}_{65}$ \\
\hline & & $E_{A A G} M_{C T G C}$ & $\mathrm{~L}_{33}, \mathrm{~L}_{37}, \mathrm{~L}_{102}, \mathrm{~L}_{204}, \mathrm{~L}_{216}$ \\
\hline & & $E_{A A G} M_{C T A C}$ & $\mathrm{~L}_{183}$ \\
\hline \multirow[t]{5}{*}{ AFLP } & STRAT without structure & $E_{A C A} M_{C T G C}$ & $L_{72}, L_{343}, L_{352}, L_{362}$ \\
\hline & & $E_{A C A} M_{C T A}$ & $L_{51}, L_{286}, L_{311}, L_{352}, L_{399}$ \\
\hline & & $E_{A A G} M_{C A G T}$ & $L_{379}, L_{399}, L_{406}, L_{450}$ \\
\hline & & $E_{A A G} M_{C T G C}$ & $L_{37}, L_{68}, L_{102}, L_{105}$ \\
\hline & & $E_{A A G} M_{C T A C}$ & $\mathrm{~L}_{127}$ \\
\hline \multirow[t]{3}{*}{ AFLP } & STRAT with structure & $E_{A C A} M_{C T G C}$ & $\mathrm{~L}_{200}$ \\
\hline & & $\mathrm{E}_{\mathrm{ACA}} \mathrm{M}_{\mathrm{CTA}}$ & $\mathrm{L}_{51}{ }^{*}$ \\
\hline & & $E_{A A G} M_{C T G C}$ & $\mathrm{~L}_{293}$ \\
\hline
\end{tabular}

L stands for locus and subscript denotes size of the band in each case.

* Locus showing association with the trait in all the three approaches. 
as well as by regression analysis thereby showing its strong association with the trait.

\section{Marker-trait association analysis using AFLP markers}

Regression analysis

Using stepwise linear regression, resin yield was regressed on all ninety available polymorphic AFLP loci with a set of forty-six P. roxburghii genotypes. Significant regression $(p<0.01)$ was observed for a total of twelve out of ninety polymorphic AFLP loci. The details of AFLP loci showing association with resin yield is given in Table 7. The associated loci each explained $97.56 \%$ of the total phenotypic variation in resin yield. The details of analysis of variance involving simple linear regression using AFLP markers are available in Table 5.

\section{Structured association test (STRAT) using AFLP markers}

\section{STRAT assuming no population structure}

Out of 250 DNA fragments derived from five AFLP primer combinations, ninety loci which were found to be polymorphic were assessed for genetic association with resin yield. Under the assumption of no population structure, a total of thirty loci were found to show significant association with resin yield. However after correcting for FDR, seventeen loci showed significant association (Table 7). Three of the associated loci including $\mathrm{E}_{\mathrm{ACA}} \mathrm{M}_{\mathrm{CTA} 51}, \mathrm{E}_{\mathrm{ACA}}$ $\mathrm{M}_{\mathrm{CTA286}}$ and $\mathrm{E}_{\mathrm{ACA}} \mathrm{M}_{\mathrm{CTA352}}$, were found to be common with those identified to be associated in regression analysis (Table 7).

\section{STRAT considering population structure}

After accounting for population stratification, a total of seventeen loci were found to be in significant association with resin yield. After correction for $\mathrm{FDR}$, three loci $\left(\mathrm{E}_{\mathrm{ACA}} \mathrm{M}_{\mathrm{CTGC200}}\right.$, $\mathrm{E}_{\mathrm{ACA}} \mathrm{M}_{\mathrm{CTA51}}$ and $\mathrm{E}_{\mathrm{AAG}} \mathrm{M}_{\mathrm{CTGC293}}$ ) showed significant association (Table 7). As a result of population stratification, the strength of association remained unaffected for the locus $\mathrm{E}_{\mathrm{ACA}} \mathrm{M}_{\mathrm{CTA51}}$ which was also found to be in significant association with the resin yield in regression analysis suggesting its strong association with the trait. Table 6 shows the comparison of the STRAT analysis for the loci showing association with resin yield both in the absence and presence of population structure. The locus $\mathrm{E}_{\mathrm{ACA}} \mathrm{M}_{\mathrm{CTA} 51}$ associated with resin yield in structured association also showed significant association with the same strength in the absence of population structure by STRAT as well as by regression analysis thereby showing its strong association with the trait.

\section{Discussion}

The hierarchial clustering using ISSR revealed four small clusters in which the grouping of genotypes was in accordance with the resin yield and suggested a high genetic divergence among the genotypes. There is a clear indication that the genotypes with similar resin yield were genetically close to each other showing the genetic basis of the trait. The UPGMA based dendrogram clustered the high and low resin yielding genotypes into different minor clusters. These clusters separated from one another at bootstrap values ranging from 78 to 99. The high bootstrap values of these clusters indicate statistical strength of the genotype relationships revealed by the cluster analysis. Low resin yielding genotypes were distributed in two clusters (cluster-II and cluster-IV) and high resin yielders were grouped together in two clusters (cluster-I and cluster-III). Grouping of the genotypes was based on their resin yield and not on the basis of their site of collection. The dendrogram could not cluster the low and high resin yielding genotypes into two broad clusters. This might be due to small ISSR dataset and lesser number of fragments. With the increase in the number of primers, the number of fragments will also increase and more informative clustering could be achieved.

Model based clustering using ISSR markers revealed the existence of five subpopulations in the germplasm based on their ancestry. Of the total genotypes, 56.60 per cent were clearly assigned to each single population whereas 43.4 per cent were categorized as having admixed ancestry which was in agreement with that earlier reported by CHO et al. (2008) using SSR markers in soybean where 56.9 per cent of the genotypes were clearly assigned to a single population and 43.1 per cent were categorized as having admixed ancestry. The grouping of $P$. roxburghii genotypes into different subpopulations had no correlation with their resin yield or their site of collection. This clearly indicated that the genotypes having similar resin yield 
had no ancestral relationship among them and were not from the same collection site. This finding further confirmed that the genotypes clustered together in the UPGMA based dendrogram did not shared any ancestral relationship with each other. Thus, the variation in resin yield among the $P$. roxburghii genotypes was not attributed to their site of collection or their ancestry.

AMOVA using ISSR showed that most of the variation in $P$. roxburghii lies within sites, a result compatible with woody perennial, out breeding plant species, especially conifers (HAMRICK et al., 1992). Population genetic differentiation is negligible $\left(F_{\mathrm{ST}}=0.005\right)$ between the studied populations/sites and indicate that there is no hindrance in the gene flow among the selected sites resulting in homogeneous genetic structures. For the interpretation of $F_{\mathrm{ST}}$, it has been suggested that a value lying in the range $0-0.05$ indicates little genetic differentiation; a value between 0.05 and 0.15 , moderate differentiation; a value between 0.15 and 0.25 , great differentiation; and values above 0.25 , very great genetic differentiation (WRIGHT, 1978; HARTL and ClaRK, 1997). The results are quite confirmatory as it is obvious that selected four sites being located nearby to each other and representing to a larger forest of Chakrata, there is well connectivity between the selected sites with respect to gene flow. The AMOVA analysis also showed that most of the variations $(95.17 \%)$ with respect to the resin yield lie within groups (created based on resin yield) than among groups $(4.83 \%)$. Low differentiation among the natural populations is frequently observed at neutral marker loci for conifers and other wind pollinated trees forming large, more or less continuous stands (HAMRICK et al., 1992). In a review, NYBOM and BARTISH (2000) assembled AMOVA derived $F_{\mathrm{ST}}$ values for about hundred plant species and confirmed the tendency of gymnosperms to have lower values of population differentiation than angiosperms. Most of the studies on geographic variation in conifers have revealed high levels of genetic variation within populations and little differentiation among the populations (YEH and ElKASSABY, 1980; WheELER and GuRIES, 1982; HiEBERT and HAMRICK, 1983; LOVELESS and HAMRICK, 1984; KIM et al., 1994; MuelleR-STARCK, 1995; AGUNDEZ et al., 1997). Usually over 90 per cent variation in tree species is localized within populations (LEDIG, 1986). The genetic differentiation among the sites was found to be negligi- ble and non significant, however significant genetic differentiation was found among the groups that were created based on resin yield. The results of AMOVA analysis using ISSR markers supported the results obtained by both UPGMA based clustering as well as model based clustering.

In the past twenty years, the major effort in breeding has changed from traditional phenotypic-pedigree-based selection systems to molecular genetics with emphasis on QTL identification and Marker Assisted Selection (MAS). MAS which uses DNA markers to select optimal genotypes, is an excellent tool for selecting beneficial genetic traits that are difficult to measure, that exhibit low heritability and/or are expressed late in development (RIBAUT and Hoisington, 1998; DaVIES et al., 2006; WILDE et al., 2007; ENDER et al., 2008; KNOLL and EJETA, 2008), as well as for assessing the genetic potential of specific genotypes prior to phenotypic evaluation (GEBHARDT et al., 2004). Molecular markers linked with QTL/major genes for traits of interest are being routinely developed in several plant species using materials derived from planned crosses such as $\mathrm{F}_{2}$, RIL, DH populations, etc. However, non-availability of mapping populations and substantial time needed to develop such populations are sometimes major limitations in the identification of molecular markers for specific traits especially in case of forest trees. In order to overcome these limitations, and as an alternative to planned populations, molecular markertrait association identifications have been conducted through the combination between the present germplasm and the regression technique (WRIGHT and Mowers, 1994; YoNASH et al., 2000; ChatterJee and Pradeep, 2003; ChatTERJEe and Mohandes, 2003; PRADEeP et al., 2007; SRIVASTAVA et al., 2007) and increasingly adopted in many plants (MAUREIRA-BUTLER et $a l .$, 2007). The germplasm-regression combined (GRC) association studies not only allow mapping of genes/QTLs with higher level of confidence, but also allow detection of genes/QTLs, which will otherwise escape detection in linkage-based QTL studies based on the planned populations. Use of regression analysis to identify the associations of molecular markers with desirable traits is increasingly being used in crops and woody plants with great success, such as Asia rice (VIRK et al., 1996), wheat (Roy et al., 2006), tea (Mishra and SEN-MANDI, 2004), AlfaAlfa (OBert et al., 2000; Maureira-Butler 
et al., 2007), mulberry (VIJAYAN et al., 2006; KAR et al., 2008), coconut (SHALINI et al., 2007), birch (WANG, 2007; WANG et al., 2008; XIA et al., 2008), oat (ACHLEITNER et al., 2008) and sea buckthorn (RUAN et al., 2009).

Dominant markers viz. ISSRs, RAPDs and AFLPs have very well been used in association mapping in various plant species (VIJAYAN et al., 2006; Roy et al., 2006; SHALINI et al., 2007). VIJAYAN et al. (2006) studied leaf yield attributing traits in Mulberry (Morus indica) and found, seven ISSR markers associated with weight of 100 leaves, seven ISSRs for internodal distance, three for leaf yield, three for chlorophyll, five for protein, two for moisture and five for total shoot length. In another report, for the identification of molecular markers associated with mite resistance in coconut, stepwise multiple regression analysis was carried out using RAPD and SSR markers and revealed three RAPD markers showing strong association with mite resistance (SHALINI et al., 2007) accounting together for 83.86 per cent of the total variation in mite resistance and 6 SSR markers accounted for 100 per cent of mite resistance. In another study, association analysis was carried out for fourteen agronomically important traits using SSR, SAMPL and AFLP markers in bread wheat (Roy et al., 2006) employing simple linear regression and multiple regression analysis.

In association mapping, presence of population structure may lead to spurious associations (BUCKLER and THORNSBERRY, 2002). Here, ISSR markers were tested for association with resin yield first assuming no population structure and then after accounting for population structure as revealed by the software STRUCTURE. When test of association was carried out assuming no population structure, 18 out of 148 polymorphic loci were identified to be associated with resin yield. As revealed by regression analysis, maximum number of loci $(44.44 \%)$ associated with resin yield were those derived from the tetra-nucleotide repeat primer UBC873 [(GACA $\left.)_{4}\right]$. Two of the associated loci $\mathrm{UBC} 83_{1319} \quad(\mathrm{p}<0.001) \quad$ and $\mathrm{UBC} 873_{661}$ $(\mathrm{p}<0.001)$ both derived from ISSR primer UBC873 were found to be common with those identified by regression analysis showing their strong association with the trait (Table 7).

In a study of northern and southern European populations carried out by SELDIN et al. (2006), the effect of controlling for population structure was examined in the analysis of putative Rheumatoid arthritis susceptibility loci applying population structure information using STRUCTURE (FALUSH et al., 2003) and STRAT (PRITCHARD et al., 2000). It was reported that some of the candidate SNPs (e.g. rs2476601 and rs1291490) survived the controlling for population stratification whereas others lose their significance (e.g. rs10838316 and rs2288774).

In the present investigation, 5 loci out of 18 survived controlling for population structure. Among the five loci that survived controlling for population structure, the strength of association for three loci (e.g. UBC809 849 , UBC873 1319 and UBC873 534 ) remained unaffected. One ISSR markers (UBC818 ${ }_{428}$ ) showed only marginal association with resin yield after accounting for population structure. The marker UBC $873_{1319}$ showed association with resin yield with the same strength even after accounting for population structure showing its true association with resin yield. This marker was also identified to be associated with resin yield in regression analysis and showed strongest association $(\mathrm{p}<0.001)$ when structured association analysis was carried out thereby showing its strong association with the trait.

Low level of genetic diversity revealed by cluster analysis could be due to the low level of polymorphism shown by AFLP marker system in the present study. Although the number of bands amplified per primer combination was high but the percent polymorphism was less.

The model based clustering of $P$. roxburghii genotypes into five subpopulations had no correlation with their resin yield thus supporting the results obtained through ISSR markers. This confirmed that the genotypes with similar resin yield had no ancestral relationship with each other therefore it indicated that the variation in resin yield was not because of shared ancestry among the $P$. roxburghii genotypes.

Analysis of molecular variance using AFLP markers also supported the results obtained using ISSR markers in the present investigation. Most of the variation in $P$. roxburghii genotypes lies within population. Negligible genetic differentiation was observed among the groups when AMOVA was carried out based on collection site whereas when AMOVA was carried out based on resin yield, significant genetic differentiation was observed among the groups with an $F_{\text {ST }}$ value 0.2422 and it was highly signifi- 
cant $(\mathrm{p}<0.001)$. The $F_{\mathrm{ST}}$ value 0.2422 indicated that there was great genetic differentiation among the groups using AFLP markers when the genotypes were grouped based on their resin yield. This supported the outcome of ISSR analysis suggesting that the variation among the $P$. roxburghii genotypes at the molecular level was correlated with the variation in resin yield and not their site of collection. This further highlighted the genetic basis of the trait.

Using stepwise linear regression, resin yield was regressed on all ninety available polymorphic AFLP loci with a set of fifty-three P. roxburghii genotypes. A total of twelve out of ninety polymorphic AFLP loci were identified to be associated with resin yield explaining 97.56 per cent of the total available variation. In an earlier report in ryegrass (Sкот et al., 2005), stepwise linear regression analysis was carried out to identify AFLP markers associated with flowering time genes. Three markers ACA_CAC_225, ACA_CTA_254 and ACA_CTA_321 were identified as significantly associated with heading date explaining more than 70 per cent of the variation in heading date.

When the test of association was carried out for AFLP markers using the program STRAT assuming no population structure, thirty loci were identified to be associated with resin yield. Among these, three loci $\left(\mathrm{E}_{\mathrm{ACA}} \mathrm{M}_{\mathrm{CTA51}}\right.$, $\mathrm{E}_{\mathrm{ACA}} \mathrm{M}_{\mathrm{CTA286}}$ and $\mathrm{E}_{\mathrm{ACA}} \mathrm{M}_{\mathrm{CTA352}}$ ) were found to be common with those identified by regression analysis. When structured association analysis was carried out one locus (e.g. $\mathrm{E}_{\mathrm{ACA}} \mathrm{M}_{\mathrm{CTA51}}$ ) survived controlling for population structure and the remaining loci lose their significance showing them to be the false positives. The marker $\mathrm{E}_{\mathrm{ACA}} \mathrm{M}_{\mathrm{CTA51}}$ which was identified to be associated in regression analysis also showed the strongest association $(\mathrm{p}<0.001)$ with resin yield and its strength of association remained unaffected even after accounting for population structure.

This study clearly reveals the genetic basis of the variation in resin yield in $P$. roxburghii. Methods to improve the accuracy of early selection at the individual level would be of considerable value for increasing the genetic gain per time unit. To achieve this objective, marker assisted selection (MAS) is the promising method which results in direct and non destructive identification of genotypes, using a diagnostic system based on molecular markers which co-segregate with the trait of interest. Selection based on molecular marker will have an enormous impact on cost reduction in breeding programs and will be of prime importance for forest products based industries, by guaranteeing quality forest products.

\section{Acknowledgements}

We are thankful to Dr. S. S. NeGi, Former Director, Forest Research Institute, Dehradun and Mr. SHASHI MALIK for providing the resin yield data for $P$. roxburghii genotypes. Thanks are also due to Mr. M. S. NEGI, TERI, New Delhi for helping us in AFLP experimentation. Financial assistance by ICFRE funded project "Characterization of Pinus roxburghii for resin yield using association studies and spiral grain formation in wood using molecular markers" [FRI-568/G\&TP-30] is also acknowledged.

\section{References}

ABDURAKHMONOV, I. Y. and A. ABDUKARIMONov (2008): Application of association mapping to understanding the genetic diversity of plant germplasm resources. International Journal of Plant Genomics, 574927.

Achleitner, A., N. A. Tinker, E. Zechner and H. Buerstmayr (2008): Genetic diversity among oat varieties of worldwide origin and associations of AFLP markers with quantitative traits. Theoretical and Applied Genetics 117: 1041-1053.

Agundez, D., B. Degen, G. Von, Wuehlisch and R. Alia (1997): Genetic variation of Aleppo pine (Pinus halepensis MiLL.) in Spain. Forest Genetics 4(4): 201-209.

Buckler, E. S. and J. M. ThornsberRy (2002): Plant molecular diversity and applications to genomics. Current Opinion in Plant Biotechnology 5: 107-111.

ChatterJee, S. N. and T. P. Mohandas (2003): Identification of ISSR markers associated with productivity traits in silkworm, Bombyx mori L. Genome 46: 438-447.

Chatterjee, S. N. and A. R. Pradeep (2003): Molecular markers (RAPD) associated with growth, yield and origin of the silkworm, Bombyx mori L. in India. Russian Journal of Genetics 39: 1365-1377.

Cho, G. T., J. Lee, J. K. Moon, M. S. Yoon, H. J. BAEK, J. H. KAnG, T. S. Kim and N. C. PAeK (2008): Genetic diversity and population structure of Korean soybean landrace [Glycine $\max$ (L.) Merr.]. Journal of Crop Science and Biotechnology 11(2): 83-90.

Coppen, J. J. W. and G. A. Hone (1995): Gum naval stores: turpentine and rosin from pine resin. FAO, Non-wood Forest Products 2: 62 p. 
Darvasi, A., A. Weintreb, V. Minke, S. Weller and M. SolLER (1993): Detecting marker QTL linkage and estimating QTL gene effect and map location using a saturated genetic map. Genetics 134: 943-951.

Davies, J., W. A. Berzonsky and G. D. LeACH (2006): A comparison of marker-assisted and phenotypic selection for high grain protein content in spring wheat. Euphytica 152: 117-134.

ENDER, M., K. TERPSTRA and J. D. Kelly (2008): Marker-assisted selection for white mold resistance in common bean. Molecular Breeding 21: 149-157.

Evanno, G., S. REgnaut and J. Goudet (2005): Detecting the number of clusters of individuals using the software STRUCTURE: a simulation study. Molecular Ecology 14: 2611-2620.

Excoffier, L., G. LaVAL and S. Schneider (2005): Arlequin ver. 3.0: An integrated software package for population genetics data analysis. Evolutionary Bioinformatics online 1: 47-50.

Excoffier, L., P. E. Smouse and J. M. Quattro (1992): Analysis of molecular variance inferred from metric distances among DNA haplotypes; Application to human mitochondrial DNA restriction data. Genetics 131: 479-491.

Falush, D., M. Stephens and J. K. Pritchard (2003): Inference of population structure using multilocus genotype data: linked loci and correlated allele frequencies. Genetics 164: 1567-1587.

Felsenstein, J. (1985): Confidence limits in phylogenies: an approach using bootstrap. Evolution 39: 783-791.

Forestry Statistics India (2011): Published by Division of Statistics, ICFRE, Dehradun. Pages: $113 \mathrm{Pp}$

Gebhardt, C., A. Ballvora, B. Walkemeier, P. OberHAGEMANN and K. SchUleR (2004): Assessing genetic potential in germplasm collections of crop plants by marker-trait association: a case study for potatoes with quantitative variation of resistance to late blight and maturity type. Molecular Breeding 13: 93-102.

GHILDIYAL, S. K., C. M. ShARMA and S. GAIROLA (2009): Environmental variation in seed and seedling characteristics of Pinus roxburghii Sarg. from Uttarakhand, India. Applied Ecology and Environmental research 7(2): 121-129.

HAMriCK, J. L., M. J. W. GodT and S. L. SHERMANBROYLES (1992): Factors influencing levels of genetic diversity in woody plant species. New Forest 6: $95-124$.

Hansen, M., T. Kraft, S. Ganestam, T. Sall and N. O. Nilsson (2001): Linkage disequilibrium mapping of the bolting gene in sea beet using AFLP markers, Genetic Research 77(1): 61-66.

Hartl, D. L. and A. G. ClARK (1997): Principles of population genetics. SinauerAssoc, Sunderland, MA, USA.

Hiebert, R. D. and J. L. HAMRICK (1983): Patterns and levels of genetic variation in Great Basin bristlecone pine, Pinus longaevea. Evolution 37(2): 302-310.
Holsinger, K. E., P. O. Lewis and D. K. Dey (2002): A Bayesian approach to inferring population structure from dominant markers. Mol. Ecol. 11: 11571164

Hong, Y. P., H. Y. KwON and I. S. KIM (2007): I-SSR markers revealed inconsistent phylogeographic patterns among populations of Japanese Red Pines in Korea. Silvae Genetica 56(1): 22-26.

Kar, P. K., P. P. SRivastava, A. K. Awasthi and S. R. URS (2008): Genetic variability and association of ISSR markers with some biochemical traits in mulberry (Morus spp.) genetic resources available in India. Tree Genetics and Genomes 4: 75-83.

Kennedy, B. W., M. Quinton and J. A. M. VANARENDONK (1992): Estimation of effects of single genes on quantitative traits. J. Anim. Sci. 70: 2000-2012.

KIM, Z. S., S. W. LEE, J. H. LIM, J. W. HWANG and K. W. KWON (1994): Genetic diversity and structure of natural populations of Pinus koraiensis (Sieb. et Zucc.) in Korea. Forest genetics 1: 41-49.

KNOLL, J. and G. EJETA (2008): Marker-assisted selection for early-season cold tolerance in sorghum: QTL validation across populations and environments. Theoretical and Applied Genetics 116: 541-553.

KraAkman, A. T. W., F. Martinez, B. Mussiraliev, F. A. VAn EeuwiJK and R. E. NIKS (2006): Linkage disequilibrium mapping of morphological, resistance, and other agronomically relevant traits in modern spring barley cultivars. Molecular Breeding 17: 41-58.

KraAkman, A. T. W., R. E. NiKs, P. M. M. M. VAN Den Berg, P. StAm and F. A. VAN EeUWiJK (2004): Linkage disequilibrium mapping of yield and yield stability in modern spring barley cultivars. Genetics, 168: 435-446.

Kremer, A., H. S. Caron, N. Cavers, G. Colpaert and GHeYsen (2005): Monitoring genetic diversity in tropical trees with multilocus dominant markers. Heredity 95: 274-280.

Kuang, H., T. E. Richardson, S. D. Carson and B. C. BONGARTEN (1998): An allele responsible for seedling death in Pinus radiata D. Don. Theor. Appl. Genet. 96: 640-644.

LEDIG, F. T. (1986): Heterozygosity, heterosis, and fitness in outcrossing plants. In: M. E. Soule (Eds.), Conservation biology: the science of scarcity and diversity, Sinauer, Sunderland, Massachusetts, USA. pp. 77-104.

LOVELESS, M. D. and J. L. HAMRICK (1984): Ecological determinants of genetic structure in plant populations. Annual review of Ecology and Systematics 15: 65-95.

Maureira-Butler, I. J., J. A. Udall and T. C. OsBORN (2007): Analyses of a multi-parent population derived from two diverse alfalfa germplasm: testcross evaluations and phenotype-DNA associations. Theoretical and Applied Genetics 115: 859-867.

Miller, A. J. and B. A. SchaAl (2006): Domestication and the distribution of genetic variation in wild 
and cultivated populations of the Mesoamerican fruit tree Spondias purpurea L. (Anacardiaceae). Mol. Ecol. 15: 1467-1480

Mishra, R. K. and S. SEn-Mandi (2004): Molecular profiling and development of DNA marker associated with drought tolerance in tea clones growing in Darjeeling. Current Science 87: 60-66.

Mueller-StarcK, G. (1995): Genetic variation in high elevation populations of Norway spruce (Picea abies [L.] Karst.) in Switzerland. Silvae Genetica 44: 356-362.

Neale, D. B. and O. Savolainen (2004): Association genetics of complex traits in conifers. Trends Plant Science 9: 325-330.

NyBOM, H. and I. V. BARTish (2000): Effects of life history traits and sampling strategies on genetic diversity estimates obtained with RAPD markers in plants. Perspectives in Plant Ecology, Evolution and Systematics 3: 93-114.

Obert, D. E., D. Z. Skinner and D. L. Stuteville (2000): Association of AFLP markers with downy mildew resistance in autotetraploid alfalfa. Molecular Breeding 6: 287-294.

Perrier, X. and J. P. JAcquemoud-Collet (2006): DARwin software. Genetic improvement of vegetatively propagated crops. http://darwin.cirad.fr/ Home.php

Pradeep, A. R., A. H. Jingade and R. S. Urs (2007): Molecular markers for biomass traits: association, interaction and genetic divergence in silkworm Bombyx mori. Biomarker Insights 2: 197-217.

Pritchard, J. K., M. Stephens and P. Donnelly (2000a): Inference of population structure using multilocus genotype data. Genetics 155: 945-959.

Pritchard, J. K., M. Stephens, N. A. RosenberG and P. DoNNELly (2000b): Association mapping in structured population. American Journal of Human Genetics 67: 170-181.

Pritchard, J. K., M., Stephens, N. A. Rosenberg and P. Donnelly (2000): Association Mapping in Structured Populations. American Journal of Human Genetics 67: 170-181.

RAWAT, A., S. BARTHWAL and H. S. Ginwal (2014a): Comparative assessment of SSR, ISSR and AFLP markers for characterization of selected genotypes of Himalayan Chir pine (Pinus roxburghii Sarg.) based on resin yield. Silvae Genetica 63 (3): 94-109.

Rawat, A., S. Barthwal and H. S. Ginwal (2014b): Association mapping for resin yield in Pinus roxburghii Sarg. Using microsatellite markers. Silvae Genetica 63 (6): 253-266.

Ribaut, J. M. and D. A. Hoisington (1998): Marker assisted selection: new tools and strategies. Trends in Plant Science 3: 236-239.

Roy, J. K., R. BANDHOPADYAY, S. Rustgi, H. S. BALYAN and P. K. GUPTA (2006): Association analysis of agronomically important traits using SSR, SAMPL and AFLP markers in bread wheat. Current Science 90(5): 683-689.

RUAN, C. J., H. LI and S. Mopper (2009): Characterization and identification of ISSR markers associ- ated with resistance to dried-shrink disease in sea buckthorn. Molecular Breeding 24: 255-268.

Seldin, M. F., R. Shigeta, P. Villoslada, C. Selmi, J. Tuomilehto, G. Silva, J. W. Belmont, L. Klareskog and P. K. Gregersen (2006): European Population Substructure: Clustering of Northern and Southern Populations. PLoS Genetics 2(9): 1339-1351.

Shalini, K. V., S. Manjunatha, P. Lebrun, A. Berger, L. Baudouin, N. Pirany, R. M. RanGANATH and D. T. PRASAD (2007): Identification of molecular markers associated with mite resistance in coconut (Cocos nucifera L.). Genome 50: 35-42.

Silbiger, R. N., S. A. Christ, A. C. Leonard, M. GARG and D. L. LATTIER (1998): Preliminary studies on the population genetics of the central stoneroller (Campostoma anomalum) from the Great Miami River Basin, Ohio. Environ. Monit. Assess. 51: 481-495.

Skot, L., M. O. Humphreys, I. Armstead, S. HeYwood, K. P. Skot, R. Sanderson, I. D. Thomas, K. H. Chorlton and N. R. S. HAmilton (2005): An association mapping approach to identify flowering time genes in natural populations of Lolium perenne (L.). Molecular Breeding 15: 233-245.

SRIVAstava, P. P., P. K. KaR, A. K. Awasthi and S. R. URS (2007): Identification and association of ISSR markers for thermal stress in polyvoltine silkworm Bombyx mori. Russian Journal of Genetics 43: 858-864.

Vijayan, K., P. P. Srivatsava, C. V. Nair, A. K. Awasthi, A. Tikader, B. Sreenivasa and S. R. Urs (2006): Molecular characterization and identification of markers associated with yield traits in mulberry using ISSR markers. Plant Breeding 125: 298-301.

Virk, P. S., B. V. Ford-Lloyd, M. T. JACKson, H. S. Pooni, T. P. Clemeno and H. J. Newbury (1996): Predicting quantitative variation within rice germplasm using molecular markers. Heredity 76: 296-304.

Vos, P., R. Hogers, M. Bleeker, M. Reijans, T. VAN DE LEE et al. (1995): AFLP: a new technique for DNA fingerprinting. Nucleic Acids Res. 23: 4407-4414.

WANG, D., Z. G. WEI, C. P. YANG and G. J. LIU (2008): Analysis and identification of SCAR molecular markers associated with birch fiber length trait. Journal of Forest Research 19: 288-292.

WANG, Y. Q. (2007): Study on Betula platyphylla long fiber trait by SSR marker technology. Dissertation for the Degree of Master, Northeast Forestry University.

Wheeler, N. C. and R. P. GuRIEs (1982): Population structure, genetic diversity and morphological variation in Pinus contorta Dougl. Canadian Journal of Forest Research 12: 595-606.

Wilde, F., V. Korzun, E. Ebmeyer, H. H. Geiger and T. Miedaner (2007): Comparison of phenotypic and marker-based selection for Fusarium head blight resistance and DON content in spring wheat. Molecular Breeding 19: 357-370. 
Williams, J. G. K., A. R. Kubelki, K. J. LivaK and S. V. TINGEY (1990): DNA polymorphisms amplified by arbitrary primers are useful as genetic markers. Nucleic Acids Res. 18: 6531-6535.

Wright, A. J. and R. P. Mowers (1994): Multiple regression for molecular-marker, quantitative trait data from large F2 a populations. Theoretical and Applied Genetics 89: 305-312.

WrIGHT, S. (1978): Evolution and the genetics of Populations ( $3^{\text {rd }}$ edition). University of Chicago Press, Chicago.

XIA, D. A., Z. G. WeI, C. P. YANG and G. J. LIU (2008): Analysis of ISSR and SCAR Markers associated with birch fiber length trait. Journal of Northeast Forestry University 39: 1-4.

Yan, G., J. Romero-Severson, M. Walton, D. D. Chadee and D. W. Severson (1999): Population genetics of the yellow fever mosquito in Trinidad: comparisons of amplified fragment length polymorphism (AFLP) and restriction fragment length polymorphism (RFLP) markers. Mol. Ecol. 8: 951-963.
YeH, F. C. and Y. A. EL-KASsAbY (1980): Enzyme variation in natural populations of Sitka spruce (Picea sitchensis). Genetic variation patterns among trees from 10 provenances. Canadian Journal of Forest Research 10: 415-422.

Yonash, N., E. D. Heller, J. Hillel and A. CAHANER (2000): Detection of RFLP markers associated with antibody response in meat-type chickens: haplotype/genotype, single-band and multiband analyses of RFLP in the major histocom-patibility complex. Journal of Heredity 91: 24-30.

Zhao, Y., H. WANG, W. Chen and Y. Li (2014): Genetic Structure, Linkage Disequilibrium and Association Mapping of Verticillium Wilt Resistance in Elite Cotton (Gossypium hirsutum L.) Germplasm Population. PLoS ONE 9(1): e86308. doi:10.1371/journal.pone.0086308

Zhivotovsky, L. A. (1999): Estimating population structure in diploids with multilocus dominant DNA markers. Mol. Ecol. 8: 907-913.

\title{
Inducing genetic variation in growth related characteristics of poplar germplasm, by producing inter-specific hybrids between $P$. alba and $P$. euphratica
}

\author{
By H. Mirzaie-Nodoushan ${ }^{*}$, A. Ghamari-Zare ${ }^{1)}$, F. TAvousi RaD ${ }^{2)}$ and M. Yousefifard ${ }^{3)}$
}

(Received $2^{\text {nd }}$ November 2015)

\begin{abstract}
Crosses were made between two Populus species to create two hybrid groups, $P$. alba $+*$ $P$. euphratica $\widehat{\sigma}$ and $P$. euphratica $+* P$. alba $\hat{\sigma}$. Aseptic immature hybrid seeds were first grown on MS medium. Hybrid seedlings were then acclimatized and grown in greenhouse conditions and transplanted to an experimental field. Growth related characteristics were recorded on 307 three years-old seedlings of new inter-spe-

\footnotetext{
1) Associ. Prof., Forests and Rangelands Research Institute, Agricultural Research, Education and Extension Organization (AREEO), Tehran, I.R. Iran.

2) M.Sc. Payam-Noor University, Isfahan, I.R. Iran.

$\left.{ }^{3}\right)$ Assist. Prof., Payam-Noor University, Tehran, I.R. Iran.

*) Corresponding author: Prof. H. MiRzaie-Nodoushan. Forests and Rangelands Research Institute, Agricultural Research, Education and Extension Organization (AREEO), Tehran, I.R. Iran. Phone: 0098-91-26662603, Fax: 0098-21-44580288.

E-Mail: nodoushan2003@yahoo.com
}

cific hybrids of six half-sib families, in order to assess possible potentials of the two hybrid groups. Double nested analysis of variance revealed significant differences between the hybrid groups and siblings based on majority of the studied characters. The hybrid groups formed two distinct groups for some of the studied characteristics which implied maternal effects of inheritance on the traits. The first hybrid group had more but shorter and closer branches than the second group. Adaxial stomata number for the two hybrid groups varied between 4.7 to 123 . Whereas, there were no such strong differences between vegetative characteristics of the two groups. The second hybrid group had a very condense layer of white fuzz on its abaxial leaf surface, inherited from its female parents. This may lead to suggest some kinds of photosynthesis and respiration functions such as leaf sub-stomatal chambers' functions for the mentioned fuzzy trichomes of 